\title{
Participação política, efeitos e resultados em políticas públicas: notas crítico-analíticas
}

\author{
$\overline{\overline{ }}$ \\ Alexander Cambraia N. Vaz \\ Projeto Democracia Participativa \\ Departamento de Ciência Política \\ Universidade Federal de Minas Gerais
}

Resumo: O artigo oferece uma discussão e um modelo de análise sobre as potenciais influências da categoria "participação política" na distribuição de bens e serviços públicos em municípios brasileiros. Mais especificamente, coteja associações entre grau de participação em nível local e qualidade da oferta de tais equipamentos em áreas específicas, notadamente, saneamento, saúde e assistência social. Para isso, em oito municípios brasileiros são levantados aspectos gerenciais cruciais que, sugere-se, são passíveis de influência por políticas de cunho participativo.

Palavras-chave: participação política; avaliação de políticas públicas; distribuição; teoria democrática; estudos de política local

\begin{abstract}
The paper discusses potential linkages between political participation and the distribution of public goods and services at the local level. It considers a relation between greater participation and a better performance on the offer of public goods by governments by analyzing variables associated to managerial aspects. The study was conduced in eight Brazilian cities.
\end{abstract}

Keywords: participation; public policies evaluation; distribution; democratic theory; local level studies 


\section{Introdução ${ }^{1}$}

Incitado, em grande medida, pela promulgação da Constituição de 1988, o fenômeno da institucionalização da participação política tem se diversificado e aumentado no Brasil, servindo de base e aporte ao desenvolvimento de literatura correlata na seara da teoria democrática contemporânea (AVRITZER, 2006; SANTOS, 1998; SANTOS e AVRITZER, 2003; COELHO e NOBRE, 2004). Grande parte dos estudos esteve voltada basicamente à investigação de fatores que condicionariam o funcionamento e o êxito de instituições participativas ${ }^{2}$, pressupondo, a partir disso, dada influência nas decisões tomadas por governos locais (VAZ, 2009, 2011; DAGNINO, 2002; FUNG \& WRIGHT, 2003; TATAGIBA, 2004). Pouca atenção tem sido dedicada, todavia, aos efeitos output dessas instituições, isto é, se, em que medida, em que sentido e sob quais condições processos e decisões em políticas públicas podem factualmente ser influenciados por procedimentos dessa natureza (VAZ e PIRES, 2011).

Este artigo se insere nessa discussão, ainda que, com um objetivo mais modesto em relação à envergadura do desafio colocado. Pretende-se, com base na metodologia de matched-pairs ${ }^{3}$, somente cotejar potenciais associações entre algumas características de determinados municípios brasileiros no tocante a variáveis ligadas às categorias "participação política" e "gestão e administração pública". Efetivamente, não se constitui como objetivo o estabelecimento factual de efeitos, impactos ou mesmo relações explícitas de causalidade entre as variáveis elencadas, mas, antes, demonstrar o comportamento de algumas variáveis de resultado em políticas públicas sob o controle de variáveis ligadas a características de participação política e a características de fundo contextual, socioeconômicas e demográficas.

O trabalho está organizado da seguinte forma. Na próxima seção, realiza-se discussão sobre o crescimento e a diversificação de políticas de participação social no Brasil, enfatizando-se, principalmente, sua presença em nível local como realidade inevitável para a gestão em políticas públicas. Em seguida, na terceira seção, discute-se alguns estudos que pretenderam avanços na análise dos efeitos destas políticas sobre a administração pública. A quarta seção explicita a metodologia de matched-pairs como uma alternativa analítica e mais uma via de estudos em relação a estes trabalhos. A quinta seção traz à baila e analisa, com

\footnotetext{
${ }^{1}$ Agradeço aos pareceristas da Revista OPINIÃO PÚBLICA pelos comentários à versão anterior deste artigo.

2 Instituições que propiciam a participação da chamada sociedade civil nas decisões sobre políticas públicas (AVRITZER, 2002). Grosso modo, dois tipos mais conhecidos são os Conselhos Gestores (GOHN, 2001; COELHO, 2004) e o Orçamento Participativo (AVRITZER e NAVARRO, 2003; AVRITZER e VAZ, 2008).

${ }^{3}$ Consiste em uma técnica de controle de variáveis e análise (VAZ e PIRES, 2011) e será mais bem explicitada na seção correlata.
} 
VAZ, A. C. N. Participação política, efeitos e resultados em políticas públicas: ...

base neste referencial metodológico, dados empíricos ligados às temáticas da participação social, da gestão pública e de caráter contextual (político e socioeconômico) de oito municípios brasileiros, a saber, Vitória da Conquista, Ilhéus, Juiz de Fora, Uberlândia, São Leopoldo, Novo Hamburgo, Poços de Caldas e Montes Claros ${ }^{4}$. A última seção é dedicada às considerações finais.

\section{Políticas participativas em voga}

Há pelo menos duas décadas, especialmente após a promulgação da Constituição de 1988, o fenômeno da participação política tem crescido e se diversificado no Brasil, especialmente ao nível municipal (TATAGIBA, 2004; GOHN, 2001; AVRITZER e NAVARRO, 2003; VAZ, 2009, 2011; DAGNINO, 2002; CUNHA, 2007). O país tem sido visto como "um laboratório de enormes dimensões" (LAVALLE, HOUTZAGER e CASTELLO, 2006:45) acerca da criação de instituições que operacionalizam a participação dos cidadãos, particularmente no desenho e implementação de políticas públicas em áreas e temática específicas (AVRITZER, 2006; SANTOS, 1998; SANTOS e AVRITZER, 2003; COELHO e NOBRE, 2004).

Pilar central desse fenômeno, a Carta de 1988 é resultado de um intenso processo de negociação entre grupos sociais diversos que atuaram sob um contexto político-econômico em plena transformação, contando com fenômenos como o fim da ditadura militar e o aumento das chances de organização de agrupamentos opositores, o estabelecimento de um sistema multipartidário e o fortalecimento de movimentos sociais de base, como o Movimento Sanitarista e a ação da Igreja Católica (SKIDMORE,1999; MAINWARING, 1999; JACOBI, 1989). O documento previu algumas novidades na política brasileira, como a prerrogativa de descentralização política e a elevação dos municípios à categoria de entes federativos autônomos; a previsão, como direito coletivo, do acesso a bens e serviços em áreas temáticas específicas, como saúde, educação e assistência social (CUNHA, 2007); bem como, a previsão e incentivo à criação de canais institucionais que permitissem a participação dos cidadãos nos processos públicos de tomada de decisão especialmente nestas áreas ${ }^{5}$ (TATAGIBA, 2004; GOHN, 2001).

\footnotetext{
4 Os dados trabalhados têm caráter inédito, tendo sido coletados em pesquisas realizadas pelo "Projeto Democracia Participativa" (Prodep), centro de estudos acerca da participação política ligado ao Departamento de Ciência Política da UFMG. Para mais informações: <www.democraciaparticipativa.org>. 5 Apenas como nota, pode-se dizer que as instituições políticas dos países da América Latina sempre foram pensadas tendo por base processos de institucionalização sócio-políticos oriundos dos países da Europa e da América do Norte (KOWARICK, 1975; SELEE E TULCHIN, 2004; OXHORN, 2004; LAVALLE, HOUTZAGER e CASTELLO, 2006). Em tempos mais recentes, entretanto, experiências específicas empreendidas na região latino-americana referentes notadamente à questão da participação política têm despertado atenção destes últimos atores, invertendo, de certa forma, o fluxo de aprendizado acerca da prática da democracia na modernidade, seja, por exemplo, numa perspectiva de "democratização da democracia" (SANTOS e AVRITZER, 2003), ou, ainda, em teorizações e análises acerca de uma
} 
As instituições participativas, um dos formatos possíveis assumidos por políticas de cunho participativo ${ }^{6}$, sendo os casos mais famosos no Brasil os "Conselhos Gestores", a experiência do "Orçamento Participativo" e as "Conferências temáticas", têm sido, desde pelo menos o início da década de 90, amplamente disseminadas pelos municípios do país (GOHN, 2001; COELHO, 2004; AVRITZER e NAVARRO, 2003; AVRITZER e VAZ, 2008; CUNHA, 2007; AVRITZER, 2008; KECK, 1992; TATAGIBA, 2004; VAZ, 2011). A Tabela 1 fornece um panorama desse fenômeno para o caso dos Conselhos Gestores:

Tabela 1

Disseminação de conselhos nos municípios brasileiros, por área de atuação

\begin{tabular}{|c|c|c|c|c|c|c|c|}
\hline Área de atuação & 2001 & 2002 & 2004 & 2005 & 2006 & 2008 & 2009 \\
\hline Saúde & $98 \%$ & $\cdots$ & $\cdots$ & $\cdots$ & $\cdots$ & $\cdots$ & $98 \%$ \\
\hline Assistência Social & $93 \%$ & $\cdots$ & $\cdots$ & $\cdots$ & $\cdots$ & $\cdots$ & $\cdots$ \\
\hline Criança e Adolesc. & $77 \%$ & $82 \%$ & $\cdots$ & $93 \%$ & $83 \%$ & $\cdots$ & $91 \%$ \\
\hline Educação & $73 \%$ & $\ldots$ & $\cdots$ & $\ldots$ & $68 \%$ & $\cdots$ & $71 \%$ \\
\hline Emprego/Trabalho & $34 \%$ & $\cdots$ & $\cdots$ & $\cdots$ & $\cdots$ & $\cdots$ & $\cdots$ \\
\hline Turismo & $22 \%$ & $\cdots$ & $\cdots$ & $\cdots$ & $\cdots$ & $\cdots$ & $\cdots$ \\
\hline Cultura & $13 \%$ & $\cdots$ & $\cdots$ & $21 \%$ & $17 \%$ & $\cdots$ & $25 \%$ \\
\hline Habitação & $11 \%$ & $\cdots$ & $14 \%$ & $18 \%$ & $\cdots$ & $31 \%$ & $43 \%$ \\
\hline Meio Ambiente & $29 \%$ & $34 \%$ & $37 \%$ & $\cdots$ & $\cdots$ & $48 \%$ & $56 \%$ \\
\hline Transporte & $5 \%$ & $\cdots$ & $\cdots$ & $\cdots$ & $\cdots$ & $6 \%$ & $6 \%$ \\
\hline Política Urbana & $6 \%$ & - & $\cdots$ & $13 \%$ & $\cdots$ & $18 \%$ & $\cdots$ \\
\hline Orçamento & $5 \%$ & $\cdots$ & $\cdots$ & $\cdots$ & $\cdots$ & $\cdots$ & $\cdots$ \\
\hline Segurança Pública & $\cdots$ & $\cdots$ & $\cdots$ & $\cdots$ & $8 \%$ & $\cdots$ & $10 \%$ \\
\hline Defesa Civil & $\cdots$ & $\cdots$ & $\cdots$ & $\cdots$ & $26 \%$ & $\cdots$ & \\
\hline Esporte & $\cdots$ & $\cdots$ & $\cdots$ & $\cdots$ & $\cdots$ & $\cdots$ & $11 \%$ \\
\hline Direitos da Mulher & $\cdots$ & $\cdots$ & $\cdots$ & $\cdots$ & $\cdots$ & $\cdots$ & $11 \%$ \\
\hline Idoso & $\cdots$ & $\cdots$ & $\cdots$ & $\cdots$ & $\cdots$ & $\cdots$ & $36 \%$ \\
\hline Juventude & . & $\ldots$ & $\cdots$ & $\cdots$ & $\cdots$ & $\cdots$ & $5 \%$ \\
\hline Direito das P.c/Def. & $\cdots$ & $\cdots$ & $\cdots$ & $\cdots$ & $\cdots$ & $\cdots$ & $9 \%$ \\
\hline
\end{tabular}

Fonte: MUNIC 01.09, IBGE.

Nota: '. .' indica dados não disponíveis.

"reforma" que estaria em curso no tocante às suas bases (SANTOS, 1998; AVRITZER, 2000; HELD, 1995).

${ }^{6}$ É mister enfatizar que, além das instituições participativas, outros canais que propiciam a participação direta dos cidadãos nos processos de tomada de decisão política foram previstos como cláusulas de grande relevância na Constituição Nacional (BENEVIDES, 1991). Cláusulas que se consubstanciaram nos instrumentos previstos da Iniciativa Popular de Lei e nas consultas populares acerca de temáticas específicas em discussão no Parlamento - o caso do Plebiscito e do Referendo. 
Conselhos Gestores são instituições compostas de forma paritária por membros do governo e da sociedade civil para deliberação sobre as bases e condições de políticas públicas específicas ${ }^{7}$ - que variam desde a temática da saúde, de assistência social, criança e adolescente, até a de patrimônio público e cultural (WAMPLER e AVRITZER, 2004; TATAGIBA, 2004; GOHN, 2001; DAGNINO, 2002). A Tabela 1 mostra que ao longo pelo menos da última década, o percentual de Conselhos tem aumentado significativamente, sobretudo os casos das áreas da saúde e assistência social, que, segundo as estimativas, já contariam ambas com Conselhos em mais de $90 \%$ das localidades nacionais. Além disso, segundo Cunha (2004), somando-se todos os Conselhos atualmente existentes, é possível estimar que existam 1,5 milhão de pessoas atuando nestes espaços, número que, como já apontado por Avitzer (2007), supera a quantidade atual de vereadores. No caso do Orçamento Participativo (OP), estima-se uma quantidade de participantes acima de 200 mil pessoas (WAMPLER e AVRITZER, 2008).

Não é difícil perceber que as instituições participativas conformam realidade inevitável para formuladores de políticas públicas, de uma maneira geral. A importância desse fato reside no pressuposto de que a distribuição de serviços e recursos teria por base uma variável de considerável peso, que é a presença dos próprios "impactados" para concordar, discordar ou mesmo apresentar propostas determinadas. Assim, a hipótese implícita nesse tipo de análise é a de que municípios nos quais se observasse um maior grau de institucionalização da participação seriam mais propensos a políticas redistributivas e a medidas voltadas ao aprimoramento do governo local, uma vez que relações mais intensas ente governo e cidadãos constituiriam pressões importantes nessas direções (PIRES e VAZ, 2010).

Tal como afirmamos em outros trabalhos, é possível dividir em duas grandes fases os estudos até hoje empreendidos no país com relação ao fenômeno da participação política (VAZ, 2009; 2011). Em uma primeira fase, que poderia ser considera laudatória, os teóricos estudaram o fenômeno pela ótica das implicações do aumento e ampliação desta participação política para a dinâmica democrática. Nos últimos anos, a literatura tem focado sua atenção em fatores que influenciariam o funcionamento das instâncias de participação, pressupondo dada relação entre seu adequado funcionamento e o grau de influência nas ações e tomadas de decisão do Estado.

\footnotetext{
${ }^{7}$ A consolidação dos Conselhos enquanto esferas de interlocução concretizou-se na busca de um padrão de relacionamento entre governo e atores sociais que promovesse a partilha efetiva de autoridade entre ambos (TATAGIBA, 2002). Há três Conselhos Gestores específicos cuja presença é obrigatória para o repasse de verbas do Governo Federal referente à política pública à qual eles se ligam. São eles, o da Saúde, o da Assistência Social e o de Direitos da Criança e Adolescente (GOHN, 2001).

8 Diversas variáveis têm sido levantadas nessa linha. Wampler e Avritzer (2004), por exemplo, chamam atenção para a influência que o tipo de partido político ou coalizão pode ter no próprio funcionamento destes espaços de acordo com o grau de importância que dão à sua presença; Avritzer (2002), assim
} 
Muito embora as pesquisas realizadas tenham contribuído para o avanço do próprio entendimento do papel das instituições participativas, estudos que tenham por foco a análise oposta, isto é, os efeitos do funcionamento das instituições participativas sobre a administração pública ainda são raros. Trabalhando nessa linha, alguns pesquisadores já pretenderam alguns avanços, tentando, de uma forma geral, entender os impactos distributivos efetivos ocorridos nos índices de vulnerabilidade e priorização de investimentos. A próxima seção se ocupa exatamente destes estudos.

\section{Analisando o papel da participação}

Algumas tentativas de associação entre a presença de instituições participativas e os resultados de políticas públicas em áreas diversas têm sido empreendidas recentemente na seara da literatura sobre participação social. 0 método base tem consistido na adoção de um conjunto de proposições que operacionalizam, de diferentes maneiras, a configuração dessas instituições como variável independente, as dimensões potenciais de impacto de suas ações e, por fim, técnicas específicas capazes de combinar essas duas variáveis sob uma perspectiva de causalidade (PIRES e VAZ, 2010).

Avritzer e Pires (2004), por exemplo, fizeram um estudo da utilização de elementos objetivos como aporte para definições orçamentárias em Belo Horizonte no âmbito do OP. Os autores mostraram que a adoção do chamado IQVU, Índice de Qualidade de Vida Urbana, serviu como ferramental importante para conferir suporte às decisões tomadas nas assembléias do programa, principalmente na perspectiva de distribuição espacial das demandas apresentadas num contexto de restrições financeiras.

Trabalhando na mesma chave de análise, Boulding e Wampler (2009) tentam estabelecer uma ligação entre existência do programa OP e melhoria do bem-estar local. As variáveis que operacionalizam o conceito de bem-estar - e que, neste sentido, são definidas como dependentes - são o IDH-M (e suas variações próprias: longevidade, renda e educação) e o índice de Gini. O OP é tomado como variável independente e dicotômica. São selecionadas outras variáveis que, teoricamente, teriam potencial explicativo sobre os resultados, em especial, a orientação ideológica do partido político no poder, a presença do PT, a região, o

como Putnam (2002), atenta para o perfil associativo dos municípios, ou sua densidade associativa; uma variável também importante, que é a de desenho, ou formato institucional, tem sido também analisada (FUNG, 2004; LUCHMANN, 2002a; TATAGIBA, 2004); Faria (2005) ressalta a importância da presença e o engajamento do gestor. Particularmente importante para este trabalho, vale trazer à baila a perspectiva de Avritzer e Navarro (2003) e Graziela e Ribeiro (2003), ao quais atentam para a capacidade administrativa e capacidade financeira para o adequado funcionamento e mesmo existência de instâncias participativas. 
VAZ, A. C. N. Participação política, efeitos e resultados em políticas públicas: ...

nível presente de desenvolvimento municipal e o orçamento per capita local. Lidando com dados de 1989-2000 e através da utilização de regressões, os autores concluem que, no geral, o peso relativo do OP para explicar melhorias no bem-estar é estatisticamente baixo e tem relação maior, no caso de disponibilidade de recursos no município (nos municípios com mais recursos, os resultados tendem a ser mais visíveis).

Zamboni (2007) também trabalha com o Orçamento Participativo como variável independente para avaliação de resultados e impactos, adotando a metodologia de comparação de pares. O autor lida especificamente com variáveis ligadas a uma concepção de corrupção no trato com o serviço público, baseando-se em dados de auditorias realizadas pela Controladoria-Geral da União em municípios brasileiros. Ele seleciona municípios semelhantes para alguns prospectos específicos, como renda per capita, população - dentre outros - e filtra aqueles com e sem OP. Sua análise comparativa revelou que os municípios com OP foram aqueles que, em sua maioria, tiveram menos indícios de práticas graves de corrupção.

Na cidade de Porto Alegre, Marquetti (2003; 2005) demonstrou que o percentual de investimentos públicos tende a aumentar à medida que se observa um maior grau de pobreza nas regiões da cidade.

Em Marquetti, Campos e Pires (2008), observamos uma série de estudos de caso de experiências de participação e seus respectivos impactos em áreas específicas. Diversos municípios são tomados como objeto de estudo em análises que lidam, em sua maioria, com o OP como objeto e investigam sua capacidade redistributiva, tomando-o, no geral, como variável independente e com significativo poder preditivo/explicativo de variações de resultados em temáticas determinadas, como a fiscal e a social.

A análise deste conjunto de estudos, que toma por objetivo o estabelecimento de uma associação entre políticas participativas e resultados em políticas públicas, incita pelo menos duas conclusões. Em primeiro lugar, estes estudos caracterizam-se por um alto grau de especialização do objeto de estudo. Este breve apanhado já foi capaz de sugerir uma concentração em um tipo específico de instituição participativa, notadamente o OP. Em segundo lugar, é possível notar uma preferência pela metodologia de estudos de caso do que por um método de cunho comparativo. Singular nesse entremeio, e compreendida como técnica alternativa cujas bases conseguem lidar diferentemente com estes elementos, potencializando diferentes tipos de análises nesse sentido, o método matched-pairs, ou análise de pares contra-factuais, tem sido cada vez mais trazido à baila por pesquisadores que trabalham na linha de aferição de resultados de instituições participativas. A próxima seção busca explicitá-lo. 


\section{Participação e políticas públicas: resultados}

A análise de pares contra-factuais pretende a comparação de municípios com características socioeconômicas e socio-demográficas semelhantes com fins de verificação de variabilidade de outras dimensões de interesse, como no caso de indicadores de oferta de serviços em áreas específicas (ZAMBONI, 2007). É um método que estabelece, portanto, variáveis de controle específicas e possibilita investigar a variação de diversos fatores para os casos em análise e atribuí-las, em alguma medida, ao comportamento das primeiras.

Tal como pontuado em Vaz e Pires (2011):

"trata-se de um procedimento que considera uma variável de interesse $\mathrm{Y}$ e uma intervenção ou tratamento $W_{i} \mathrm{~W}_{i}$ pode assumir valores 0 ou 1 , mas nunca ambos. Zero indica a ausência do tratamento, em nosso caso a ausência (ou insucifência) de instituições participativas. Portanto, $Y_{i}=Y(W)$ será o resulto de uma variável de interesse (por exemplo, qualidade da gestão ou investimentos em saúde, etc.) quando a variável de tratamento esteja presente ou não em um dado município i. A questão central, então, se torna a diferença entre $Y(1)$ e $Y(0)$. Entretanto, para um município com o tratamento, apenas $Y^{i}(1)$ é observável, enquanto que o resultado contrafactual - por exemplo, investimento em saúde - na ausência do tratamento para o mesmo município $Y(0)$ não é observável e, por isso, precisa ser estimado utilizando-se 'os resultados observados em um município muito semelhante não submetido ao tratamento. Partindo do princípio de que a única diferença relevante entre os municípios é a sua condição em relação à ausência e presença do tratamento - isto é, ausência ou presença (ou qualidade) de instituições participativas -, quaisquer diferenças entre os resultados e o desempenho observado entre os municípios pode ser associado à operação de instituições participativas" (VAZ e PIRES, 2011:4 - no prelo).

Recentemente, alguns pesquisadores têm utilizado a técnica com fins de verificar variabilidades em termos de participação política em municípios diversos do Brasil. Baiochi et al (2006), por exemplo, empreendem um estudo sobre o OP e seus possíveis impactos distributivos em municípios brasileiros. Trabalhando com dados de 1991-2000, os autores tomam o programa como variável dummy e realizam uma análise comparativa direta entre municípios com e sem OP. Isto é, são selecionadas cidades dotadas de resultados semelhantes para algumas variáveis ditas de controle, como tamanho populacional, renda per capita e 
orçamento municipal e realiza-se uma análise comparativa de alguns indicadores de resultado em áreas específicas, como as fiscal/tributária e social. O OP, assim, é tomado como variável independente, mas seu peso para a melhoria de indicadores de resultado é mensurado basicamente a partir de casos nos quais o programa não está presente.

Trabalhando com a técnica, vale a pena mencionar o trabalho de Pires e Tomás (2007), que adotam a metodologia de pares para análise de efetividade de instâncias participativas, mas ampliando o objeto de pesquisa. Os autores tomam por unidade de análise a presença de um conjunto de instituições participativas, composto pelo OP, Conselhos gestores e outras. A esse conjunto é dado o caráter de variável independente e, ao tomá-lo por base, os autores empreendem uma comparação de pares de municípios, selecionados de acordo com variáveis de controle específicas, como o tamanho populacional, a renda per capita, os níveis de associativismo, entre outras, para resultados específicos de indicadores das áreas de arrecadação tributária e dispêndios em serviços públicos, como saúde, educação e assistência social. Os resultados encontrados para os casos estudados sugeriram uma correlação positiva entre presença de instituições participativas e melhoramento destes indicadores.

Na mesma linha, Pires e Vaz (2010) empreendem uma análise sistemática de uma amostra de municípios brasileiros, comparando variações no número de instituições participativas e resultados para alguns indicadores de cunho fiscal, administrativo e social. Os autores elaboram uma proposta de índice que tenta medir variações no grau de presença dessas instituições em determinado município, chamado de Índice Municipal de Institucionalização da Participação (IMIP).

A observação destes estudos permite concluir determinado avanço na análise da associação entre instituições participativas e resultados de políticas públicas, especialmente no tocante a técnica de pares. Pelo que se percebe, a utilização dessa metodologia permite um referencial claro de comparabilidade entre casos diferenciados, controlados por determinados fatores elencados como relevantes. Além disso, dentre os próprios estudos que utilizam a técnica, existe uma preocupação em diversificar, também, os objetos de investigação, sendo, no caso, as instituições participativas. Isso é particularmente verdadeiro para os dois últimos trabalhos recuperados. O que se percebe, no geral, assim, é que a utilização da técnica de pares implica uma diferenciação em relação às técnicas anteriores no tocante, principalmente, à diversificação dos objetos e casos sob investigação, bem como quanto ao controle empreendido para estabelecimento de comparações. 


\section{Desenvolvendo a análise: a participação em foco}

Com base no exposto, fica claro que a utilização de uma metodologia tal qual a de pares-contrafactuais pode ensejar contribuições relevantes na temática da participação política, notadamente na sua relação com resultados apresentados por políticas públicas específicas. Face às dificuldades impostas pelo próprio objetivo dos estudos, bem como no que concerne ao estabelecimento de relações de causalidade ou mesmo de associação entre variáveis nas ciências sociais de uma forma geral, o matched-pairs revela-se uma alternativa plausível, principalmente em função das características mencionadas na última seção.

Tal constatação sugere que vale a pena utilizar essa técnica para cotejar os objetivos desse trabalho, especialmente em função do número, diversidade e tipos de casos sob análise, seja no tocante às cidades, seja no tocante à operacionalização da categoria "participação política". Com vistas a tal tarefa, algumas características importantes da metodologia devem ser analisadas e levadas em consideração.

O primeiro pressuposto concerne ao Estado ou região de origem das cidades. Deve-se priorizar a escolha de casos que comunguem essa primeira característica, porque estudos anteriores, como em Avritzer (2007), já demonstraram que há uma relevante variabilidade, por exemplo, no grau de associativismo entre os Estados e entre regiões, como nos casos do Estado do Rio Grande do Sul e da região Nordeste. Assim, ao se escolher casos pertencentes a Estados e regiões iguais, poder-se-á atribuir um fraco grau de influência dessa característica em eventuais variações das variáveis de resultado.

O segundo pressuposto consiste na escolha de variáveis específicas para controle de similaridade entre os casos. Neste quesito, pode-se supor a escolha de variáveis discriminantes, como tamanho populacional, IDH, PIB Per capta, índice de Gini, dentre outros de caráter sócio-demográfico e socioeconômico. O terceiro pressuposto consiste na suposição de que, além dos elementos socio-demográficos e socioeconômicos, os conjuntos de municípios podem compartilhar características importantes dos seus contextos político e econômico. Assim, para além da relevância da escolha das variáveis descritas, é importante uma análise descritiva das características dos respectivos contextos econômico, político e social dos casos elencados para estudo. 
VAZ, A. C. N. Participação política, efeitos e resultados em políticas públicas: ...

\section{Estratégia de análise}

Efetivamente, vale observar, o atendimento completo a estas restrições metodológicas configura desafio significativo quando buscamos casos empíricos para análise. O que se pretende, para este trabalho, é conhecer, sob condições de relativa semelhança para algumas variáveis (o que poderíamos chamar de "controle"), o comportamento de determinadas variáveis de resultado em uma perspectiva comparada, diferenciando os casos em relação aos seus respectivos graus de participação - considerando municípios segundo o grau de participação política. Seguindo esses critérios e em função da disponibilidade de dados, conseguimos escolher um total de 8 municípios para comparação em pares.

\section{Contextos e semelhanças}

Os dados apresentados para análise neste artigo compreendem um conjunto de oito municípios pesquisados no âmbito de trabalhos realizados pelo "Projeto Democracia Participativa", núcleo de estudos vinculado ao Departamento de Ciência Política da UFMG. A Tabela 2 explicita as informações dos casos elencados:

Tabela 2

Dados socioeconômicos e demográficos para os municípios da amostra

\begin{tabular}{|c|c|c|c|c|c|c|c|c|c|}
\hline UF & Município & População & $\begin{array}{c}\text { Taxa de } \\
\text { urbanização }\end{array}$ & $\begin{array}{l}\text { Renda } \\
\text { per } \\
\text { capita }\end{array}$ & Gini & IDH-M & $\begin{array}{c}\text { Taxa } \\
\text { alfabetizaçã } \\
0\end{array}$ & $\begin{array}{l}\text { Sobrevivência } \\
\text { até } 60 \text { anos }\end{array}$ & $\begin{array}{c}\text { PIB } \\
(\mathrm{p} / \\
1.000 \\
\text { hab - } \\
\mathrm{R} \$) \\
\end{array}$ \\
\hline BA & $\begin{array}{l}\text { Vitória da } \\
\text { Conquista }\end{array}$ & 262494 & 85,9 & 204,9 & 0,63 & 0,708 & 80,22 & 71,23 & 5.166 \\
\hline BA & Ilhéus & 222127 & 73,0 & 170,22 & 0,64 & 0,703 & 79,4 & 73,54 & 3.805 \\
\hline$M G$ & $\begin{array}{c}\text { Juiz de } \\
\text { Fora }\end{array}$ & 456796 & 99,2 & 419,4 & 0,58 & 0,828 & 95,3 & 83,17 & 8.091 \\
\hline$M G$ & Uberlândia & 501214 & 97,6 & 389,32 & 0,56 & 0,83 & 94,55 & 84,99 & 10.253 \\
\hline RS & $\begin{array}{c}\text { São } \\
\text { Leopoldo }\end{array}$ & 193547 & 99,7 & 370,06 & 0,55 & 0,805 & 95,22 & 77,68 & 7.847 \\
\hline RS & $\begin{array}{c}\text { Novo } \\
\text { Hamburgo }\end{array}$ & 236193 & 98,2 & 390,95 & 0,55 & 0,809 & 94,99 & 79,74 & 9.683 \\
\hline$M G$ & $\begin{array}{c}\text { Poços de } \\
\text { Caldas }\end{array}$ & 135627 & 96,5 & 435,56 & 0,56 & 0,841 & 94,32 & 89,5 & 8.963 \\
\hline$M G$ & $\begin{array}{l}\text { Montes } \\
\text { Claros }\end{array}$ & 306947 & 94,2 & 245,43 & 0,62 & 0,783 & 90,08 & 82,7 & 5.840 \\
\hline
\end{tabular}

Fonte: IBGE Munic 2009; IpeaData 
A Tabela 2 revela que as cidades elencadas para comparação estão conformadas com pelo menos dois pressupostos restritivos da metodologia em pauta. Em primeiro lugar, cada par de municípios advém não apenas da mesma região, mas do mesmo Estado. Esse fato é importante porque já indica que, pelo menos em certa medida, variações significativas em relação ao grau de associativismo tendem a ser amenizadas ${ }^{9}$. Em segundo lugar, existem semelhanças entre alguns indicadores socioeconômicos de base para cada par de casos.

No que tange ao quesito populacional, observamos diferenciações significativas nos pares Poços de Caldas/ Montes Claros e São Leopoldo/ Novo Hamburgo - especialmente neste último caso, no qual a diferença supera os $100 \%$. Não obstante, em função da semelhança para os demais indicadores, podemos afirmar que essas discrepâncias podem ser amenizadas. Além disso, esse argumento também é reforçado ao considerarmos que esses valores se encontram nas mesmas faixas populacionais quando consideramos as indicações e normativas de órgãos como o IBGE e o Ipea, por exemplo ${ }^{10}$.

O segundo indicador considerado consiste na taxa de urbanização dos municípios. Neste caso, observa-se que, no geral, eles se caracterizam majoritariamente por contextos urbanos, com uma taxa média de urbanização de 93,2\%. A única diferença significativa é encontrada no primeiro par, referente aos municípios de Vitória da Conquista e Ilhéus. Além desse aspecto, os casos elencados se caracterizam por uma renda per capita que tende a variar entre os pares. As semelhanças mais significativas são encontradas nos casos Juiz de Fora/ Uberlândia e São Leopoldo/ Novo Hamburgo, com uma diferença média de 6,7\%. Os demais pares, a seu turno, apresentam diferenças relativamente maiores. 0 par Vitória da Conquista/ IIhéus apresenta uma discrepância de 16,9\% e o par Poços de Caldas/ Montes Claros conta com um percentual de 77\%. O fato desse último percentual ser significativo pode ser compensado, ainda que em parte, pelo fato de que ambos os municípios apresentam uma renda per capita relativamente alta, isto é, não é o caso de um apresentar uma renda muito baixa e o outro uma renda muito alta, mas podemos dizer que a faixa é praticamente a mesma.

Quando observamos os indicadores de Gini e IDH municipal, constatamos relativa semelhança para todos os pares. No geral, a média do Gini ficou em 0,59, o que indica que, em termos de desigualdade local, os casos encontram-se numa

\footnotetext{
${ }^{9}$ Reconhece-se, logicamente, que dentro de um mesmo Estado pode haver diferenciações entre regiões específicas, o que levaria a diferenciações também para esta variável. Poços de Caldas, por exemplo, localiza-se no sul de Minas Gerais, ao passo que Montes Claros se localiza no Norte. Não obstante, as análises têm demonstrado que essas variações intra-estaduais tendem a ser menos significativas em relação àquelas de caráter inter-estaduais. Vide Avritzer (2007).

10 Especialmente nas pesquisas do IBGE, como os Censos e as PNADS, é possível observar que uma das faixas populacionais básicas corresponde a municípios com população entre 100 mil e 500mil habitantes.
} 
VAZ, A. C. N. Participação política, efeitos e resultados em políticas públicas: ...

posição intermediária, já que, para este índice, a proximidade do valor 1 significa aumento das desigualdades. A maior média, de 0,64, concerne ao par Vitória da Conquista/ Ilhéus, ao passo que a menor média concerne ao par São Leopoldo/ Novo Hamburgo, com 0,55. No caso do IDH-M, observa-se uma média geral de 0,78 aproximadamente, indicando situação relativamente favorável em termos de desenvolvimento humano, se considerarmos que a média dos municípios brasileiros não passa de 0,49. Neste caso, a proximidade do valor 1 indica melhoria do conjunto de elementos mensurados, sendo que a maior média, de 0,829, concerne ao par Juiz de Fora/ Uberlândia, ao passo que a pior média (que, ainda assim, é melhor que a média nacional), concerne ao par Vitória da Conquista/ Ilhéus, com 0,7 .

Os dois indicadores seguintes, Taxa de alfabetização e Probabilidade de sobrevivência até os 60 anos, reforçam o caráter de semelhança entre os municípios analisados. Não se observa, por exemplo, diferenças significativas dentre os pares no que tange à taxa de alfabetização, sendo que melhor média, de 95,1\%, fica com o par São Leopoldo/ Novo Hamburgo, e a pior média, 79,81\%, com o par Vitória da Conquista/ IIhéus. Vale dizer, a média geral, de 90,51\%, é notavelmente maior do que média nacional, de 78,1\%. Ao analisarmos o indicador demográfico de sobrevivência até os 60 anos, também não notamos diferenças significativas dentre os pares, sendo a maior média, de 86,1, observada no par Poços de Caldas/Montes Claros, e a pior média vista no par Vitória da Conquista/ Ilhéus, com 72,3. Também para este indicador, vale dizer, a média geral, de 80,3, é maior do que a média nacional de 76,1, aproximadamente.

Em último lugar, como forma de demonstrar semelhança entre os pares elencados, foi selecionado o indicador do $\mathrm{Pib}$ por mil habitantes. No geral, os municípios têm um Pib de mais de $\mathrm{R} \$ \mathbf{7 . 0 0 0 , 0 0}$ para cada grupo de 1000 habitantes. Pode-se afirmar, ademais, que existe uma discrepância média de aproximadamente $\mathrm{R} \$ 2.500,00$ para cada par, muito embora os municípios contemplados em cada um se encontrem em faixas deveras semelhantes. O par Poços de Caldas/ Montes Claro, por exemplo, está numa faixa média de R\$ $7.000,00$, ao passo que os municípios do par Vitória da Conquista/ Ilhéus encontram-se numa faixa média de $\mathrm{R} \$ 4.500,00$.

No geral, a partir dos dados apresentados, podemos afirmar que os municípios elencados para análise comungam de semelhanças significativas para os indicadores trazidos à baila, e que está em consonância com os dois pressupostos restritivos básicos do modelo de matched-pairs para análise comparativa. Entretanto, para além dessa análise de cunho quantitativo, vale a pena verificar, também, se estes municípios comungam de histórias semelhantes em relação a transformações de caráter político, econômico e mesmo social. 
A importância disso reside no fato de que grande parte dos estudos sobre políticas participativas têm apontado que as iniciativas de estabelecimento dessas políticas concerne, em grande medida, aos governos (WAMPLER e AVRITZER, 2008). Estes últimos é que teriam capacidade de estabelecer canais institucionais para participação - como os Conselhos Gestores e outras iniciativas, como o OP, os Planos Diretores, dentre outros - e incentivar o estreitamento das relações com os cidadãos. Os estudos têm apontado que existe uma "vontade política" maior dos partidos de esquerda em realizar tal tarefa, comparativamente aos tradicionais partidos de direita. Assim, cada par será analisado em relação aos seus respectivos contextos político-econômicos.

\section{O par Vitória da Conquista/ IIhéus}

Em termos econômicos, Vitória da Conquista e Ilhéus são cidades significativamente distintas. Na primeira, a base econômica municipal concerne ao comércio e prestação de serviços. Nas últimas décadas, observa-se relevante expansão industrial, fazendo com que o município se localize, regionalmente, dentre aqueles que mais se desenvolveram. Ilhéus, a seu turno, conta com a agricultura como base econômica, especialmente na plantação de cacau. Pode-se dizer que os principais desenvolvimentos industriais resvalam na tentativa de aumento da produção do produto.

Politicamente, Ilhéus tem sido governada, pelo menos nos últimos 30 anos, por grupos tradicionalistas de direita. Apenas em uma gestão o controle foi assumido por um grupo de centro-direita, na gestão de Antônio Olimpo, do PDT. Já em Vitória da Conquista, o governo tem ficado a cabo de grupos esquerdistas com cada vez maior intensidade desde o fim da ditadura. Existe considerável atuação de movimentos sociais e um papel importante desempenhado pelas Igrejas, tanto católicas, quanto evangélicas.

\section{O par Juiz de Fora/ Uberlândia}

A análise deste par permite perceber informações relevantes. Economicamente, Juiz de Fora caracteriza-se pelo incentivo a políticas de industrialização, bem como pelo incentivo ao comércio de bens e serviços, sendo que só o setor de indústrias compõe quase $48 \%$ do PIB municipal. Uberlândia conta principalmente com o setor de serviços como um componente relativamente alto do PIB municipal, muito embora a cidade também se ancore, ainda que em menor grau, na atividade agropecuária como pilar de desenvolvimento.

Em termos políticos, observa-se em Juiz de Fora uma política consistente e sistemática de incentivo à participação política desde pelo menos a 
VAZ, A. C. N. Participação política, efeitos e resultados em políticas públicas: ...

redemocratização. A partir da década de 1970, houve um crescimento importante do número de associações e sindicatos municipais, e na década de 1990, as administrações que se sucederam incentivaram políticas de descentralização, em especial pela presença de partidos de tendências de esquerda no poder. Em Uberlândia observa-se uma alternância de poder entre partidos de tendência esquerdista e de direita, especialmente na década de 90. Governos do PT, por exemplo, enfrentaram significativas dificuldades para implantação da política de Orçamento Participativo no município, especialmente em função de oposições advindas da própria estrutura administrativa local.

\section{O par São Leopoldo/ Novo Hamburgo}

Os municípios de São Leopoldo e Novo Hamburgo comungam de um tipo específico de atividade econômica, que é a indústria de calçados. Seus respectivos parques industriais se igualam em nível de produtividade, bem como têm históricos semelhantes de crescimento e desenvolvimento, ocorridos principalmente nas décadas de 1960, 1970 e 1980. Uma diferença importante, no entanto, é observada a partir dos anos 1990, quando Novo Hamburgo tende a diversificar sua atividade econômica, em especial com investimentos específicos nos setores de serviço e educação.

Politicamente, pelo menos desde a década de 1990, ambas as cidades têm sido governadas por partidos de centro-direita. Novo Hamburgo, em especial, tem contado com revezamentos entre partidos como PSDB, PMDB e PDT. Já em São Leopoldo, pelo menos nos últimos anos têm sido observadas determinadas mudanças neste padrão. A última gestão, composta por partidos como o PT, o PC do $\mathrm{B}$ e o PV, causou uma ruptura na presença contínua de gestões ocupadas pelo PMDB e PTB que se prolongavam desde pelo menos a década de 1980. Além disso, desde a década de 1970 já se observava maior efervescência de movimentos sociais e associações na busca por participação nos processos decisórios, sendo criado, já na época, o chamado "Conselho de Desenvolvimento Comunitário".

\section{O par Poços de Caldas/ Montes Claros}

Os municípios de Poços de Caldas e Montes Claros estão localizados em regiões distintas de Minas Gerais, ao sul e ao norte. Historicamente, cidades da região sul são mais ricas que as do norte, mas Montes Claros é uma das mais importantes cidades de sua região e do próprio Estado. Politicamente, ambas foram governadas por partidos em sua maioria de direita, principalmente PFL e PMDB. Em 2001, porém, Poços de Caldas passou a ser governada pelo PT, mas substituído pelo DEM para a gestão seguinte. Montes Claros, por sua vez, passou a 
ser governada por uma coalizão entre PT e PSB a partir de 2005. Desde a gestão de 2001, Poços de Caldas já contava com experiências de OP, ao passo que em Montes Claros o programa só teve a sua primeira rodada efetiva em 2008.

\section{Operacionalizando a categoria "participação política"}

Além de indicadores socioeconômicos e contextos políticos, a metodologia em pauta indica a necessidade de controle das variáveis de interesse para comparação. Neste trabalho, essa variável consiste na categoria "participação política", composta de mais de uma variável, como será visto. Neste caso, existe uma inversão de lógica para comparação. Se nas variáveis anteriores procuramos demonstrar semelhanças entre os municípios de cada par, neste caso é preciso demonstrar discrepâncias entre cada um.

A própria análise dos contextos políticos de cada município já forneceu pistas importantes para uma visão geral do grau de associativismo nestes locais. Com base nestes históricos, podemos observar que, por exemplo, Vitória da Conquista tem maior propensão à adoção e ao desenvolvimento de políticas participativas do que Ilhéus. Neste mesmo sentido, os históricos levam a especular que Juiz de Fora, São Leopoldo e Poços de Caldas são cidades com maior tendência participativa do que seus respectivos pares. Não obstante, é preciso uma medida de mensuração da categoria "participação política" que perpasse estas observações e indique, objetivamente, o quanto a participação ocorre nestes lugares.

Monitoramento e variáveis

Para os fins deste artigo, a participação política será operacionalizada através da construção e correlação de três indicadores simples, apresentados e discutidos em outro trabalho, ainda que sob focos e objetivos específicos (PIRES e VAZ, 2010). O primeiro indicador refere-se à "densidade da participação política" . IPDENS. Ele mensura a quantidade de instituições participavas existentes no município e é dado por:

$$
\text { IPDENS }=(\text { CONSMED *1) }+(\text { OP * CONSMED })+(\text { OUTRA * }(\text { CONSMED/3 }))
$$

\section{(1)}

O indicador é dado pelo somatório do número médio de Conselhos Gestores presentes no município (CONSMED) nas gestões municipais escolhidas, e o resultado da multiplicação desse valor pela presença ou ausência de OP $(O P=0$ ou 1 ), bem como pelo número de outras instituições participativas existentes (OUTRA = 0 ou 1), sendo que, neste caso, divide-se a variável pelo terço, conferindo-Ihe 
VAZ, A. C. N. Participação política, efeitos e resultados em políticas públicas: ...

menor peso relativo, já que, no geral, essas instituições tendem a contribuir menos para o grau de participação do que as anteriores (AVRITZER e NAVARRO, 2003; KECK, 1992). A média de Conselhos (CONSMED) é utilizada como proxy geral o incremento marginal do OP tende a ser maior do que o de Conselhos, em termos de variabilidade do grau de participação.

O segundo indicador, IPDIVER, busca captar a diversidade de instituições participativas presentes no município, bem como a variedade de áreas de políticas públicas sob "cobertura"de políticas de cunho participativo. Ele é dado por:

$$
\text { IPDIVER }=\text { OP + OUTRA + CONSVARD [escala: } 0 \text { a 3] }
$$

\section{(2)}

A diversidade de instituições e áreas de políticas públicas sob enfoque participativo é captado pelo somatório da existência (ou não) de OP (OP = O ou 1), a existência (ou ausência) de outras instituições participativas (OUTRA = 0 ou 1) e, por fim, uma medida (CONSVARD) que correlaciona municípios que contam com o mínimo de Conselhos Gestores, notadamente aqueles requeridos por lei para o repasse de recursos, aos municípios que, além destes últimos, já tenham implantado, por "vontade própria", Conselhos Gestores em outras áreas temáticas. Se o município não contempla sequer os obrigatórios, ele não pontua. Se, na média, contempla apenas os Conselhos obrigatórios, ou um volume de pelo menos 3 Conselhos, ele pontua em 1. Se o município possui, na média, além dos obrigatórios, até mais 10 Conselhos, ele consegue 2 pontos. Se ele possui, na média, mais de 13 Conselhos, a pontuação é de 3 pontos (o somatório de 13 Conselhos é um número médio observado em outros estudos, PIRES e VAZ, 2010).

O terceiro indicador, IPDUR, busca mensurar a longevidade, ou a durabilidade, das instituições participativas em determinado município. Alguns estudos já demonstraram uma correlação positiva entre o tempo de duração de entidades participativas e o grau de "pressão" exercida sobre os governos (WAMPLER e AVRITZER, 2008; GRAZIA e RIBEIRO, 2003). Ela é dada por:

$$
\text { IPDUR } \left.=\text { OPDUR + OUTRADUR +((CONSDIFINT/\%CONSDIFINT })^{*} y=3\right)
$$

\section{(3)}

A medida básica para este indicador é o "número de gestões. Soma-se, neste caso, o número de gestões consecutivas em que no OP esteve presente (OPDUR), o número de gestões consecutivas em que outras instituições estiveram presentes (OUTRADUR) e, por fim, uma medida simples sobre a durabilidade dos Conselhos Gestores (CONSDIFINT), que calcula a diferença bruta de Conselhos existentes em uma gestão em relação a gestões anteriores, dividida pelo valor 
percentual dessa diferença (com fins de amenizar o efeito do crescimento do número de Conselhos). Esse resultado é multiplicado por uma constante y de valor 3 (medida que expressa o número de Conselhos obrigatórios, exigidos por lei). 0 cálculo dessa variável é ligeiramente diferente do que em outras oportunidades (PIRES e VAZ, 2010).

Após o cálculo desses indicadores, é feito um procedimento simples de normalização numa escala de 0 a 1 , com fins de facilitar a análise e a compreensão dos valores encontrados. Em seguida, estabelece-se uma soma simples entre cada um conforme visto abaixo:

\section{(IPDENS + IPDIVER + IPDUR)/3 = grau associativismo município}

(4)

O valor encontrado é uma variante de escala 0 a 1 , sendo que, quanto mais próximo de 1 , pode-se presumir maior o grau de associativismo e de propensão a políticas participativas do município. A seu turno, quão mais próximo de 0 , menores tendem a ser tal propensão.

A análise dos dados

Os dados utilizados referem-se a três gestões municipais: o período 1997. 2000, o período 2001-2004 e, por fim, a gestão 2005-2008. Como já afirmado, são dados coletados através de pesquisa específica e que, ademais, seguem complementados por dados secundários, como a base Munic do IBGE. A análise dos dados para o primeiro indicador, o IPDENS, medição da densidade associativa dos municípios, está apresentada na Tabela 3: 
VAZ, A. C. N. Participação política, efeitos e resultados em políticas públicas: ...

\section{Tabela 3}

Número de Conselhos por gestão e presença de Orçamento Participativo e outras instituições participativas nos municípios - indicador IPDENS

\begin{tabular}{|c|c|c|c|c|c|c|c|c|c|}
\hline \multirow[b]{2}{*}{ UF } & \multirow[b]{2}{*}{ Município } & \multicolumn{4}{|c|}{ Número de Conselhos por gestão } & \multirow{2}{*}{ OP } & \multirow{2}{*}{ OUTRA } & \multicolumn{2}{|c|}{ IPDENS } \\
\hline & & $\begin{array}{l}1997- \\
2000\end{array}$ & $\begin{array}{l}2001- \\
2004\end{array}$ & $\begin{array}{l}2005- \\
2008\end{array}$ & $\begin{array}{c}\text { Média } \\
\text { Conselhos }\end{array}$ & & & Absoluto & Normalizado \\
\hline $\mathrm{BA}$ & $\begin{array}{l}\text { Vitória da } \\
\text { Conquista }\end{array}$ & 20 & 21 & 21 & 20,7 & 1 & 1 & 48,2 & 0,735 \\
\hline BA & IIhéus & 16 & 17 & 19 & 17,3 & 0 & 0 & 17,3 & 0,264 \\
\hline$M G$ & Juiz de Fora & 20 & 22 & 25 & 22,3 & 1 & 1 & 52,1 & 0,691 \\
\hline MG & Uberlândia & 3 & 15 & 17 & 11,7 & 1 & 0 & 23,3 & 0,309 \\
\hline RS & São Leopoldo & 7 & 10 & 15 & 10,7 & 1 & 1 & 24,9 & 0,609 \\
\hline RS & Novo Hamburgo & 14 & 15 & 19 & 16,0 & 0 & 0 & 16,0 & 0,391 \\
\hline MG & Poços de Caldas & 5 & 13 & 23 & 13,7 & 1 & 1 & 31,9 & 0,648 \\
\hline MG & Montes Claros & 7 & 12 & 20 & 13,0 & 0 & 1 & 17,3 & 0,352 \\
\hline
\end{tabular}

Fonte: Pesquisa Democracia, Desigualdade e Políticas Públicas no Brasil, 2009 - PRODEP/UFMG

O que pode ser afirmado pela análise desses dados é que, através da medição do IPDENS, existem diferenciações importantes dentre os pares de municípios. Como ilustração, os casos de Vitória da Conquista e Ilhéus, podem ser considerados emblemáticos. Enquanto a primeira alcançou um valor de 0,735, a outra pontuou por volta de 0,264. Consistentemente, pode-se observar que os demais pares se diferenciam de maneira significativa, exatamente neste sentido, sendo que Juiz de Fora, São Leopoldo e Poços de Caldas encontram-se em situação relativamente melhor.

\section{Tabela 4}

Variabilidade da quantidade e tipo de instituições participativas - indicador IPDIVER

\begin{tabular}{|c|c|c|c|c|c|c|c|c|}
\hline \multirow[b]{2}{*}{ UF } & \multirow[b]{2}{*}{ Município } & \multicolumn{3}{|c|}{ CONSVARD } & \multirow{2}{*}{ OP } & \multirow{2}{*}{ OUTRA } & \multicolumn{2}{|c|}{ IPDIVER } \\
\hline & & $\begin{array}{c}\text { Média } \\
\text { Conselhos }\end{array}$ & $\begin{array}{c}\text { Contempla } \\
\text { obrigatórios }\end{array}$ & Pontuação & & & Absoluto & Normalizado \\
\hline BA & Vitória da Conquista & 20,7 & Sim & 3 & 1 & 1 & 5 & 0,625 \\
\hline BA & Ilhéus & 17,3 & Sim & 3 & 0 & 0 & 3 & 0,375 \\
\hline MG & Juiz de Fora & 22,3 & Sim & 3 & 1 & 1 & 5 & 0,625 \\
\hline MG & Uberlândia & 11,7 & Sim & 2 & 1 & 0 & 3 & 0,375 \\
\hline RS & São Leopoldo & 10,7 & Sim & 2 & 1 & 1 & 4 & 0,571 \\
\hline RS & Novo Hamburgo & 16,0 & Sim & 3 & 0 & 0 & 3 & 0,429 \\
\hline MG & Poços de Caldas & 13,7 & Sim & 3 & 1 & 1 & 5 & 0,625 \\
\hline MG & Montes Claros & 13,0 & Sim & 2 & 0 & 1 & 3 & 0,375 \\
\hline
\end{tabular}

Fonte: Pesquisa Democracia, Desigualdade e Políticas Públicas no Brasil, 2009 - PRODEP/UFMG 
Assim como a tendência encontrada no indicador anterior, existe discrepância entre os pares no que tange à diversidade de instituições presentes nos seus respectivos municípios. Isso é verdadeiro exatamente para as cidades elencadas anteriormente como estando em melhor situação em termos de densidade associativa: Vitória da Conquista, Juiz de Fora, São Leopoldo e Poços de Caldas (Tabela 4).

Em último lugar, o indicador ligado à durabilidade das instituições, IPDUR, pode ser visto na Tabela 5:

Tabela 5

Duração, em número de gestões, das instituições participativas dos municípios da amostra - indicador IPDUR

\begin{tabular}{|c|l|c|c|c|c|c|c|c|}
\hline \multicolumn{2}{|c|}{} & \multicolumn{3}{c|}{ CONSDIFINT } & \multirow{2}{*}{ OPDUR } & \multirow{2}{*}{ OUTRADUR } & \multicolumn{2}{c|}{ IPDUR } \\
\cline { 1 - 4 } UF & \multicolumn{1}{|c|}{ Município } & $\begin{array}{c}\text { Dif \# } \\
\text { Conselhos }\end{array}$ & $\%$ & Valor & & & Absoluto & Normalizado \\
\hline BA & $\begin{array}{l}\text { Vitória da } \\
\text { Conquista }\end{array}$ & 1 & 5,0 & 0,60 & 2 & 1 & 3,60 & $\mathbf{0 , 8 8 2}$ \\
\hline BA & Ilhéus & 3 & 18,8 & 0,48 & 0 & 0 & 0,48 & $\mathbf{0 , 1 1 8}$ \\
\hline MG & Juiz de Fora & 5 & 25,0 & 0,60 & 1 & 1 & 2,60 & $\mathbf{0 , 7 0 5}$ \\
\hline MG & Uberlândia & 14 & 466,7 & 0,09 & 1 & 0 & 1,09 & $\mathbf{0 , 2 9 5}$ \\
\hline RS & São Leopoldo & 8 & 114,3 & 0,21 & 1 & 3 & 4,21 & $\mathbf{0 , 9 0 9}$ \\
\hline RS & Novo Hamburgo & 5 & 35,7 & 0,42 & 0 & 0 & 0,42 & $\mathbf{0 , 0 9 1}$ \\
\hline MG & Poços de Caldas & 18 & 360,0 & 0,15 & 1 & 1 & 2,15 & $\mathbf{0 , 6 4 0}$ \\
\hline MG & Montes Claros & 13 & 185,7 & 0,21 & 0 & 1 & 1,21 & $\mathbf{0 , 3 6 0}$ \\
\hline
\end{tabular}

Fonte: Pesquisa Democracia, Desigualdade e Políticas Públicas no Brasil, 2009 - PRODEP/UFMG

Os dados mostram, uma vez, mais a tendência observada anteriormente. Neste caso, uma diferença significativa foi observada em relação ao par São Leopoldo e Novo Hamburgo e a menor diferença dentre o par Poços de Caldas e Montes Claros. Ao fim, podemos estabelecer o cálculo final para os municípios da amostra, conforme se observa na Tabela 6: 
VAZ, A. C. N. Participação política, efeitos e resultados em políticas públicas: ...

Tabela 6

Média comparada dos indicadores de instituições participativas dos municípios da amostra

\begin{tabular}{|c|c|c|c|c|c|c|}
\hline UF & Município & IPDENS & IPDIVER & IPDUR & $\begin{array}{c}\text { Média } \\
\text { pares }\end{array}$ & $\begin{array}{c}\text { Média } \\
\text { geral }\end{array}$ \\
\hline BA & $\begin{array}{c}\text { Vitória da } \\
\text { Conquista }\end{array}$ & 0,735 & 0,625 & 0,882 & $\mathbf{0 , 7 4 7}$ & $\mathbf{0 , 1 9 9}$ \\
\hline BA & Ilhéus & 0,264 & 0,375 & 0,118 & $\mathbf{0 , 2 5 2}$ & $\mathbf{0 , 0 6 7}$ \\
\hline MG & Juiz de Fora & 0,691 & 0,625 & 0,705 & $\mathbf{0 , 6 7 4}$ & $\mathbf{0 , 1 8 4}$ \\
\hline MG & Uberlândia & 0,309 & 0,375 & 0,295 & $\mathbf{0 , 3 2 6}$ & $\mathbf{0 , 0 8 9}$ \\
\hline RS & São Leopoldo & 0,609 & 0,571 & 0,909 & $\mathbf{0 , 6 9 7}$ & $\mathbf{0 , 1 6 8}$ \\
\hline RS & $\begin{array}{c}\text { Novo } \\
\text { Hamburgo }\end{array}$ & 0,391 & 0,429 & 0,091 & $\mathbf{0 , 3 0 3}$ & $\mathbf{0 , 0 6 4}$ \\
\hline MG & $\begin{array}{c}\text { Poços de } \\
\text { Caldas }\end{array}$ & 0,648 & 0,625 & 0,640 & $\mathbf{0 , 6 3 8}$ & $\mathbf{0 , 1 4 5}$ \\
\hline MG & Montes Claros & 0,352 & 0,375 & 0,360 & $\mathbf{0 , 3 6 2}$ & $\mathbf{0 , 0 8 3}$ \\
\hline
\end{tabular}

Fonte: Pesquisa Democracia, Desigualdade e Políticas Públicas no Brasil, 2009 - PRODEP/UFMG

Os dados da Tabela 6 são factualmente relevantes do ponto de vista do referencial teórico-metodológico aqui aportado. Em primeiro lugar, ao observamos a variável média pares, analisamos a pontuação relativa alcançada por cada município seguindo a fórmula (4), sob uma perspectiva relativa entre os casos de cada par. Assim, vale observar que, muito embora sejam semelhantes sob diversos aspectos, tal como pontuado linhas acima, existe uma tendência sistemática de diferenciação dos municípios pareados no que tange à adoção de políticas participativas, dado que suas respectivas pontuações sistematicamente se aproximaram mais do valor 1 , do que os seus respectivos pares.

Em segundo lugar, a variável média geral estabelece uma comparação entre todos os casos da amostra. Assim, podemos afirmar que, relativamente, para o conjunto de dados, Vitória da Conquista alcança a maior pontuação em termos participativos $(0,199)$, seguida de Juiz de Fora $(0,184)$, São Leopoldo $(0,168)$ e Poços de Caldas $(0,145)$. A menor pontuação deu-se no município de Novo Hamburgo (0,064), que ficou, inclusive, ligeiramente menor que a de Ilhéus $(0,067)$, o que pode ser explicado, ainda que em parte, pelo fato de llhéus ter aportado uma média de Conselhos (CONSMED) pouco maior que a de Novo Hamburgo nas últimas três gestões, respectivamente, 17,3 e 16 Conselhos por gestão.

A observação final para os dados apresentados no que tange à operacionalização da categoria "participação política" fornece indicações claras para utilização da técnica de matched-pairs. Como demonstrado linhas acima, os municípios da amostra comungam características específicas no tocante às 
dimensões política, econômica e social. Dados e indicadores como Gini, IDH-M, população, PIB, dentre os demais vistos, apresentaram uma relativa semelhança que permitiu embasar tal afirmação.

Entretanto, ao analisarmos os contextos político e econômico de cada caso, notou-se algumas discrepâncias importantes. Em especial, para os casos de Vitória da Conquista, Juiz de Fora, São Leopoldo e Poços de Caldas, observou-se uma participação relativamente maior no comando político de partidos de tendência centro-esquerda, ao passo que, para os demais casos, essa tendência foi mais forte em relação a partidos de centro-direita. Além disso, diferenças econômicas importantes se apresentaram, sendo que esses municípios apresentaram maior tendência à adoção de políticas de diversificação econômica do que os seus respectivos pares.

É interessante observar que, ao operacionalizarmos a categoria participação política, essas tendências puderam ser quantificadas. A metodologia levou em consideração elementos como a presença de tipos e volumes específicos de instituições participativas nos municípios, e sua duração ao longo do tempo. Ao cabo, observa-se que os municípios que foram governados em maior medida por partidos de centro-esquerda e que buscaram políticas de diversificação de suas respectivas atividades econômicas, constituem exatamente aqueles que, para esta amostra, apresentaram melhores resultados quanto ao incentivo à adoção de políticas de cunho participativo.

Esses resultados sugerem que vale a pena cotejar mais dados que possam sustentar essa relação. Em especial, dados sobre resultados de políticas públicas em áreas específicas podem ser trabalhados. A intenção, vale relembrar, não consiste no estabelecimento efetivo de correlação e de relações explícitas de causalidade entre tais dimensões, mas, antes, verificar factualmente a situação da oferta de bens e serviços dessa natureza em municípios com graus diferenciados de participação política, considerando a semelhança e, portanto, a tendência à diminuição de efeitos de variáveis intervenientes específicas, quais sejam, aquelas de caráter socioeconômico e demográfico elencadas linhas acima.

\section{A situação de oferta de bens e serviços públicos}

Para a aferição dos resultados em políticas públicas dos municípios considerados, optamos pela estratégia de escolher dimensões específicas de análise nas quais a literatura tem apontado graus relevantes de participação social. Em primeiro lugar, a área da saúde, lidando, especificamente, com a temática do saneamento básico. Diversos estudos já apontaram que movimentos em prol da sistematização e implementação efetiva de políticas de saúde no Brasil remontam, pelo menos, a década de 1970, com especial foco no chamado Movimento 
VAZ, A. C. N. Participação política, efeitos e resultados em políticas públicas: ...

Sanitarista. Grosso modo, este movimento teve fundamental importância para a discussão das disposições constitucionais que fundaram as bases do SUS (Sistema Único de Saúde), por exemplo.

A segunda dimensão concerne à área de assistência social. Essa temática tem ganhado importância e status efetivo de política pública principalmente na última década no país e já se tem demonstrado que, factualmente, é um campo que conta com relevante grau de envolvimento e participação social. Por fim, pretendemos cotejar dados relacionados à legislação e instrumentos de planejamento público dos municípios, dado que podem expressar o compromisso dos governantes em legislar, por exemplo, normas relacionadas ao estabelecimento de planos plurianuais e de planos de investimentos locais de longo prazo.

\section{Saneamento básico}

Para a análise de dados sobre saneamento básico, foram escolhidas algumas variáveis importantes de expressar a situação em determinado município, levando em consideração uma perspectiva temporal. Isso quer dizer que se pretende, não somente, a análise dos indicadores, mas, principalmente a observação de sua transformação ao longo do tempo. Para todos os casos, nessa dimensão, considera-se a família como unidade básica de análise. Além disso, com fins de análise, serão esquematizadas duas operações básicas para a comparação dos municípios. Primeiramente, utiliza-se uma operação de comparação das médias das diferenças observadas entre valores aferidos dos indicadores dentre cada par. Essa diferença consiste apenas no somatório das diferenças observadas entre cada par de municípios para cada ano. Em segundo lugar, ainda considerando os municípios dentre cada par, mensura-se a variabilidade da média observada ao longo do período considerado.

O primeiro indicador a ser observado concerne ao tipo de escoadouro disponível às famílias em seus respectivos domicílios. Neste caso, considera-se o percentual de famílias que têm escoadouro a céu aberto, ou seja, a quantidade de famílias que não têm acesso a qualquer tipo de saneamento em seus domicílios e lançam seus dejetos diretamente na rua, em córregos, rios e lagos. As informações estão apresentadas na Tabela 7: 
Tabela 7

Percentual de famílias que vivem em domicílio com escoadouro a céu aberto

\begin{tabular}{|c|c|c|c|c|c|}
\hline UF & Município & $\mathbf{1 9 9 8}$ & $\mathbf{2 0 0 1}$ & $\mathbf{2 0 0 5}$ & $\mathbf{2 0 0 8}$ \\
\hline BA & $\begin{array}{c}\text { Vitória da } \\
\text { Conquista }\end{array}$ & 18,58 & 15,75 & 13,70 & 12,04 \\
\hline BA & Ilhéus & 36,09 & 30,19 & 29,04 & 22,11 \\
\hline MG & Juiz de Fora & 2,17 & 1,73 & 2,21 & 2,61 \\
\hline MG & Uberlândia & - & 4,70 & 3,24 & 2,97 \\
\hline RS & São Leopoldo & 20,92 & 25,49 & 18,42 & 14,35 \\
\hline RS & $\begin{array}{c}\text { Novo } \\
\text { Hamburgo }\end{array}$ & 35,06 & 34,75 & 31,76 & 27,06 \\
\hline MG & $\begin{array}{c}\text { Poços de } \\
\text { Caldas }\end{array}$ & - & 9,74 & 5,59 & 4,72 \\
\hline MG & Montes Claros & 8,38 & 5,49 & 4,23 & 3,97 \\
\hline
\end{tabular}

Fonte: DataSUS. Disponível em: <www.datasus.gov.br>. Acesso em: 25 maio 2011.

Os dados indicam que, no período 1998 a 2008, existem diferenças importantes dentre os pares que valem ressaltar. Desde logo, destaca-se que para que a comparação para todos os pares seja possível, os dados serão computados para o período acima de 2001, pois para pelo menos dois casos não há informações disponíveis. Ponderado isso, primeiramente, vale analisar a diferença média de percentual.

Ao considerarmos o primeiro par, Vitória da Conquista/Ilhéus, identificamos que essa diferença, para o período em voga, é de aproximadamente 13,28\%, sendo uma média de 13,83\% para Vitória da Conquista e de 27,11\% para Ilhéus. Essa diferença observada informa que, em média, essa última cidade tem 13,28\% a mais de famílias que não têm acesso ao tipo de serviço considerado do que a primeira. No caso do segundo par, Juiz de Fora e Uberlândia, a diferença média é 1,45\%, sendo que média da primeira, Juiz de Fora, é de 2,19\% e a média da última, Uberlândia, é de 3,64\%. No caso do terceiro par, São Leopoldo e Novo Hamburgo, a diferença média é $15,1 \%$, sendo o percentual da primeira cidade de $19,42 \%$ e o da segunda, 31,19\%. Para o último par, a diferença média observada é de 2,12\%, sendo os percentuais de 6,68\% para Poços de Caldas e de 4,56\% para Montes Claros.

Os dados aferidos fornecem pistas para analisar a situação dos municípios em relação aos resultados de políticas públicas e o grau de participação política. Observa-se que, no geral, o percentual médio para esse indicador nos municípios nos quais se aferiu maior grau de participação é de $10,53 \%$. Por sua vez, nos demais municípios, esse percentual é de 16,63\%. Ademais, se considerarmos os pares individualmente, veremos que, para os três primeiros, nos municípios nos 
VAZ, A. C. N. Participação política, efeitos e resultados em políticas públicas: ...

quais se constatou grau significativo de participação política, também constatou-se melhores informações para o indicador considerado. A única exceção reside no último, caso no qual a cidade menos "participativa", Montes Claros, apresentou melhores dados do que a mais "participativa", Poços de Caldas. Não obstante, é importante observar que a diferença média para este caso específico pode ser relativizada se considerarmos que, em 2001, Poços de Caldas tinha um percentual de 9,74\% de famílias na situação considerada e Montes Claros 5,49\%. Todavia, em 2008 o percentual de Poços de Caldas caiu para 4,72\%, indicando uma diminuição média de 2,51\%. Para Montes Claros, muito embora também se tenha observado queda dos percentuais, passando para 3,97\%, o ritmo da queda foi significativamente menor, de 0,76\%.

Outro indicador que vale a pena ser utilizado para a dimensão saneamento e saúde concerne à qualidade da água consumida e disponível às famílias. Neste caso, a fonte da água pode servir de proxy para aferição dessa qualidade e o indicador concerne ao percentual de famílias cujo acesso à água se dá por poços ou nascentes. A Tabela 8 fornece informações neste sentido:

\section{Tabela 8}

Percentual de famílias cuja fonte de água consiste em poço ou nascente

\begin{tabular}{|c|l|c|c|c|c|}
\hline UF & \multicolumn{1}{|c|}{ Município } & $\mathbf{1 9 9 8}$ & $\mathbf{2 0 0 1}$ & $\mathbf{2 0 0 5}$ & $\mathbf{2 0 0 8}$ \\
\hline BA & $\begin{array}{l}\text { Vitória da } \\
\text { Conquista }\end{array}$ & 12,56 & 14,93 & 13,54 & 12,80 \\
\hline BA & Ilhéus & 8,66 & 14,50 & 16,31 & 13,99 \\
\hline MG & Juiz de Fora & 2,35 & 4,12 & 3,49 & 3,08 \\
\hline MG & Uberlândia & - & 2,34 & 2,55 & 2,58 \\
\hline RS & São Leopoldo & 0,39 & 1,02 & 1,22 & 1,18 \\
\hline RS & $\begin{array}{l}\text { Novo } \\
\text { Hamburgo }\end{array}$ & 8,07 & 8,78 & 6,07 & 5,74 \\
\hline MG & $\begin{array}{l}\text { Poços de } \\
\text { Caldas }\end{array}$ & - & 1,35 & 1,12 & 3,40 \\
\hline MG & Montes Claros & 2,44 & 2,19 & 7,39 & 9,27 \\
\hline
\end{tabular}

Fonte: DataSUS. Disponível em: <www.datasus.gov.br>. Acesso em: 25 maio 2011.

Seguindo o modelo de análise adotado, é possível observar um padrão na variação dos dados, levando em consideração o indicador anterior. Municípios nos quais houve maior grau de participação são também aqueles que apresentaram resultados relativamente melhores. No caso do primeiro par, por exemplo, observamos uma diferença média entre os municípios de $1,18 \%$, sendo de $13,75 \%$ para Vitória da Conquista e de 14,94\% para Ilhéus. Apesar de a diferença 
observada ser relativamente pequena, vale mencionar que, enquanto a primeira cidade mostra um padrão de involução do indicador, expressando melhoria do percentual de famílias com acesso a água potável, a segunda cidade mostra uma evolução, isto é, uma piora do percentual de famílias sem acesso a água de qualidade.

Ao observamos o segundo par, constatamos que essa tendência parece ser consistente para os demais municípios em comparação. Ao passo que, em Juiz de Fora, o percentual médio de famílias cuja fonte de água consiste em poços e nascentes é de 3,56\%, em Uberlândia, esse valor é de 2,49\%; mas, na primeira cidade, observa-se uma tendência de queda cuja média é de aproximadamente $0,52 \%$, ao passo que na outra existe uma tendência de aumento médio de 0,12\%. Para o terceiro par, observamos uma diferença percentual média de $6,05 \%$, sendo 0,81\% em relação ao município de São Leopoldo e de 6,86\% para Novo Hamburgo. O último par congrega tendência semelhante para a diferença média, que é de 4,32\%, sendo uma média de 1,96\% para Poços de Caldas e de 6,28\% para Montes Claros.

Um terceiro indicador sobre saúde e saneamento básico importante a se considerar nas comparações aqui empreendidas concerne ao percentual de famílias que vivem em áreas com lixo a céu aberto, isto é, em áreas que não contam com uma estrutura adequada de recolhimento e tratamento do lixo produzido. Os dados seguem na Tabela 9:

Tabela 9

Percentual de famílias que vivem em áreas com lixo a céu aberto

\begin{tabular}{|c|l|c|c|c|c|}
\hline UF & \multicolumn{1}{|c|}{ Município } & $\mathbf{1 9 9 8}$ & $\mathbf{2 0 0 1}$ & $\mathbf{2 0 0 5}$ & $\mathbf{2 0 0 8}$ \\
\hline BA & $\begin{array}{l}\text { Vitória da } \\
\text { Conquista }\end{array}$ & 17,12 & 12,58 & 9,89 & 6,59 \\
\hline BA & Ilhéus & 34,65 & 29,83 & 26,64 & 15,44 \\
\hline MG & Juiz de Fora & 0,05 & 0,39 & 0,17 & 0,08 \\
\hline MG & Uberlândia & - & 1,38 & 0,38 & 0,23 \\
\hline RS & São Leopoldo & 2,72 & 5,31 & 3,24 & 0,56 \\
\hline RS & $\begin{array}{l}\text { Novo } \\
\text { Hamburgo }\end{array}$ & 3,60 & 3,77 & 0,02 & 0,22 \\
\hline MG & $\begin{array}{l}\text { Poços de } \\
\text { Caldas }\end{array}$ & - & 1,20 & 0,43 & 0,18 \\
\hline MG & Montes Claros & 6,10 & 3,15 & 2,51 & 1,88 \\
\hline
\end{tabular}

Fonte: DataSUS. Disponível em: <www.datasus.gov.br>. Acesso em: 25 maio 2011. 
VAZ, A. C. N. Participação política, efeitos e resultados em políticas públicas: ...

Considerando a situação dos municípios do primeiro par, observamos uma diferença média de $14,28 \%$ no percentual de famílias que vivem em áreas sem tratamento de lixo, sendo o percentual de 9,69\% para Vitória da Conquista e de 23,97\% para llhéus. Para o segundo par, observamos uma diferença média de $0,44 \%$, sendo $0,22 \%$ para Juiz de Fora e de 0,66\% para Uberlândia. No terceiro par, a diferença média é de 0,3\%, sendo de 3,04\% para São Leopoldo e de 3,34\% para Novo Hamburgo. Por fim, no último par, encontramos uma diferença média de $1,19 \%$, sendo de 0,6\% para Poços de Caldas e de 2,51\% para Montes Claros.

Esse conjunto de resultados permite suscitar uma relação entre o nível de participação política nos municípios e os resultados em políticas públicas em áreas específicas, sendo, neste caso, para a área de saneamento e saúde. Vale ressaltar que essa relação não é estabelecida de maneira causal, mas que os dados indicam uma situação sistematicamente melhor em saneamento básico para os municípios com maior grau de participação política, muito embora todos os pares comunguem características relevantes para a sua caracterização. Os resultados incitam a análise de outras dimensões relevantes em políticas públicas, tal como as políticas de assistência social.

\section{Assistência Social}

A análise da assistência social é importante pela própria relevância da temática e em função do ativismo político que Ihe confere base. Em especial, muito mais do que a oferta efetiva de serviços, é importante analisar a capacidade gerencial dos municípios em relação a esse campo. Em geral, a despeito de sua relevância, a área de assistência social tende a ser tratada com menor importância do que outras áreas mais consolidadas, como saúde e educação. Assim, pode-se supor que os gestores que investem na área demonstram maior preocupação com questões como as vulnerabilidades sociais, fome e miséria, do que aqueles que relegam a área à condição de menor importância relativa.

Algumas variáveis são relevantes para a mensuração de capacidade gerencial e serão comparadas, sendo que, neste caso, há informações disponíveis para os anos 2005 e 2009. A primeira variável concerne à caracterização do órgão gestor da assistência social no município. A Tabela 10 fornece informações neste sentido: 


\section{Tabela 10}

\section{Caracterização do órgão gestor da assistência social nos municípios da amostra}

\begin{tabular}{|c|c|c|c|}
\hline UF & Município & 2005 & 2009 \\
\hline BA & $\begin{array}{l}\text { Vitória da } \\
\text { Conquista }\end{array}$ & Secretaria municipal exclusiva & Secretaria municipal exclusiva \\
\hline BA & Ilhéus & $\begin{array}{c}\text { Secretaria em conjunto com outra } \\
\text { política }\end{array}$ & $\begin{array}{c}\text { Secretaria municipal em conjunto com outra } \\
\text { política }\end{array}$ \\
\hline MG & Juiz de Fora & Secretaria municipal exclusiva & Secretaria municipal exclusiva \\
\hline MG & Uberlândia & $\begin{array}{l}\text { Secretaria em conjunto com outra } \\
\text { política }\end{array}$ & $\begin{array}{l}\text { Secretaria municipal em conjunto com outra } \\
\text { política }\end{array}$ \\
\hline RS & São Leopoldo & Secretaria municipal exclusiva & Secretaria municipal exclusiva \\
\hline RS & Novo Hamburgo & Setor subordinado a outra Secretaria & Secretaria em conjunto com outra política \\
\hline MG & Poços de Caldas & Secretaria exclusiva & Secretaria municipal exclusiva \\
\hline MG & Montes Claros & Secretaria exclusiva & Secretaria municipal exclusiva \\
\hline
\end{tabular}

Fonte: Munic 05 e 09 - IBGE

Os dados da Tabela 10 mostram os dados do órgão gestor para os pares. No caso do primeiro par, observamos que, enquanto em Vitória da Conquista existe uma estrutura administrativa exclusiva para lidar com as políticas da área, em Ilhéus essa estrutura, embora existente, é compartilhada com outra área. O compartilhamento, vale dizer, pode ser prejudicial à gestão e implicar menor eficiência, já que recursos como computadores, telefones, carros, dentre outros, imprescindíveis para a administração, em geral não ficam totalmente disponíveis aos técnicos e gestores das pastas.

O segundo par conta com um padrão semelhante, sendo que, em Juiz de Fora, a Secretaria é exclusiva e, em Uberlândia, ela é compartilhada, uma situação observada em 2005 e em 2009. No terceiro par, observamos que já em 2005, São Leopoldo possuía uma Secretaria exclusiva para a política, enquanto que, em Novo Hamburgo, existia um setor subordinado a uma Secretaria se outra área. Em 2009, parece ter havido breve transformação nessa última cidade, com a criação de uma Secretaria para a área que, ainda assim, compartilha estrutura com outra Secretaria, situação relativamente pior do que em São Leopoldo. Em último lugar, não se encontrou diferença significativa para as cidades, sendo que, desde 2005, novo Hamburgo também conta com uma Secretaria exclusiva para a Assistência Social.

Esses dados são instigantes do ponto de vista das potenciais relações entre a categoria participação política e os resultados em políticas públicas, especialmente porque, como já dito, a área de assistência social está há pouco tempo sendo estruturada no país, principalmente através do ativismo e constante apelo daqueles a ela ligados. Neste sentido, vale a pena continuar a investigação, verificando o comportamento de outras variáveis, sendo que outra variável de 
VAZ, A. C. N. Participação política, efeitos e resultados em políticas públicas: ...

relevância na perspectiva de gestão e administração, diz respeito à frequência de revisão, monitoramento e avaliação do plano municipal de assistência social. Este plano, vale dizer, está presente em todos os municípios aqui analisados, mas sua revisão e avaliação ocorre em periodicidades diferenciadas, sendo que períodos mais longos podem ser mais prejudiciais à eficiência na prestação de serviços e gestão da área. A Tabela 11 elucida as informações nessa linha:

Tabela 11

Periodicidade do monitoramento e avaliação do plano municipal de assistência social

\begin{tabular}{|c|l|c|c|}
\hline UF & \multicolumn{1}{|c|}{ Município } & $\mathbf{2 0 0 5}$ & $\mathbf{2 0 0 9}$ \\
\hline BA & $\begin{array}{l}\text { Vitória da } \\
\text { Conquista }\end{array}$ & Mensal & Mensal \\
\hline BA & Ilhéus & Anual & Anual \\
\hline MG & Juiz de Fora & Semestral & Mensal \\
\hline MG & Uberlândia & Semestral & Bimestral \\
\hline RS & São Leopoldo & Mensal & Mensal \\
\hline RS & Novo Hamburgo & $\begin{array}{c}\text { Não é monitorado e } \\
\text { avaliado }\end{array}$ & Anual \\
\hline MG & Poços de Caldas & Mensal & Semestral \\
\hline MG & Montes Claros & Anual & Semestral \\
\hline
\end{tabular}

Fonte: Munic 05 e 09 - IBGE

Para essa variável, também há variações importantes nos resultados apresentados em cada município. Em relação ao primeiro par, ao passo que Vitória da Conquista realiza mensalmente o monitoramento e avaliação de seu plano municipal de assistência social, a cidade de llhéus realiza uma vez ao ano, uma situação mantida desde 2005. No caso do segundo par, Juiz de Fora realiza semestralmente a revisão do plano em 2005, e, em 2009, a periodicidade é mensal. A seu turno, Uberlândia também realiza esta ação semestralmente em 2005 e, em 2009, realiza uma vez ao bimestre.

No caso do terceiro par, desde 2005, São Leopoldo realiza monitoramento e avaliação mensal do plano municipal de assistência social, e no caso de Novo Hamburgo, em 2005 a cidade sequer realiza esta ação, e só passou a fazê-lo em 2009, ainda que anualmente. Por último, o quarto par mostra certa inversão. Em 2005, Poços de Caldas tem uma periodicidade mensal de avaliação de seu plano e passa a uma periodicidade semestral em 2009. No caso de Montes Claros, essa frequência passou de anual em 2005, para semestral, em 2009. 
O conjunto dos dados mostra, uma vez mais, uma tendência a que os municípios nos quais ocorre um grau relativamente maior de participação social, são aqueles nos quais ocorre, também, situação relativamente melhor nos resultados em políticas públicas, sendo, nesses casos, relacionados à capacidade de gestão das políticas de assistência social. Esses resultados sugerem, igualmente, que outros dados podem ter comportamento semelhante para o campo em tela.

Outra variável relevante para análise no tocante à capacidade de gestão da assistência social consiste na existência ou não de definição legal de um percentual do orçamento do município para a área. Esse elemento pode indicar que, ao longo do tempo, pas políticas do campo não serão abruptamente interrompidas por falta de recursos financeiros. Na assistência social, vale dizer, essa perspectiva de continuidade é de suma importância, dado que lida com o acompanhamento de famílias e indivíduos ao longo do tempo por profissionais, como os psicólogos, profissionais de saúde etc. A Tabela 12 contém informações neste sentido:

Tabela 12

\section{Existência de definição legal de percentual do orçamento do município para a assistência social}

\begin{tabular}{|c|l|c|c|}
\hline UF & \multicolumn{1}{|c|}{ Município } & $\mathbf{2 0 0 5}$ & $\mathbf{2 0 0 9}$ \\
\hline BA & $\begin{array}{l}\text { Vitória da } \\
\text { Conquista }\end{array}$ & Não & Sim \\
\hline BA & Ilhéus & Não & Sim \\
\hline MG & Juiz de Fora & Sim & Sim \\
\hline MG & Uberlândia & Não & Não \\
\hline RS & São Leopoldo & Não & Sim \\
\hline RS & Novo Hamburgo & Sim & Não \\
\hline MG & Poços de Caldas & Não & Sim \\
\hline MG & Montes Claros & Não & Não \\
\hline
\end{tabular}

Fonte: Munic 05 e 09 - IBGE

Os dados fornecem indicações claras sobre o tipo de comprometimento dos municípios com a continuidade de ações na área, independentemente de governos. No primeiro par, vemos que os municípios tomam "caminhos" semelhantes ao longo do tempo, dado que, em 2005, nenhum tinha percentual definido, o que muda em 2009. No segundo par, observamos que, para os dois anos considerados, Juiz de Fora tinha a definição orçamentária, ao passo que em nenhum momento Uberlândia adotou tal procedimento. No terceiro par, a situação é peculiar: enquanto em São Leopoldo houve mudança no sentido da definição legal, em Novo Hamburgo a situação se inverteu e o município, que contava com uma definição 
VAZ, A. C. N. Participação política, efeitos e resultados em políticas públicas: ...

legal em 2005, em 2009 não contava mais. Por fim, no último par, Poços de Caldas passou a ter definição legal em 2009, enquanto Montes Claros não teve em momento algum.

O conjunto de dados para a área de assistência social leva a suposições similares àquelas produzidas na análise sobre saneamento e saúde. Parece que, para todos os casos analisados, no geral, municípios nos quais se aferiu maior grau de incidência da categoria participação política são também aqueles nos quais se percebe melhor capacidade, investimento e, principalmente, comprometimento, para a gestão das políticas de assistência social. Essa situação incide sobre municípios que se assemelham em diversas outras categorias, especialmente aquelas associadas aos indicadores socioeconômicos e políticos. Vale ressaltar que essas observações não permitem afirmar a presença de alguma relação entre as variáveis, embora os dados forneçam pistas para a formulação de suposições nessa linha.

Legislação municipal e planejamento público

Além da área específica de assistência social, o gestor municipal deve ser capaz de administrar políticas importantes para a sociedade. Recursos das áreas de saúde, educação, construção, dentre diversas outras, devem ser eficientemente equacionados, com fins de garantir bom percurso de gastos dos recursos públicos. Essa eficiência está ligada, em grande medida, à capacidade gerencial geral do município, especialmente ao seu comprometimento com o planejamento público. 0 planejamento público é peça fundamental para estruturação de uma administração eficiente e capaz de apresentar resultados plausíveis para a oferta de bens e serviços públicos nas diversas temáticas existentes.

Dessa forma, cabe verificar em que medida os municípios analisados apresentam determinados quesitos capazes de atuar como proxy para a capacidade de gestão municipal. A primeira dimensão a ser analisada nesse caso concerne ao setor de habitação e ao tipo de atenção que o gestor municipal confere à questão. A existência de políticas de habitação é considerada porque tende a exigir do gestor um significativo compromisso e organização fiscal e tributária para ser efetivada. Ao mesmo tempo, exige uma significativa capacidade de planejamento e a elaboração de planos de médio e longo prazos para o desenvolvimento do município.

A primeira variável a ser analisada para essa dimensão é a existência ou não de cadastro informatizado de indivíduos e famílias a serem beneficiados segundo linhas de corte específicas. A existência do cadastro informatizado serve como indicador do tipo e grau de organização do gestor. A Tabela 13 apresenta informações para esse aspecto: 
Tabela 13

Existência de cadastro informatizado para estruturação de política habitacional no município

\begin{tabular}{|c|l|c|c|}
\hline UF & \multicolumn{1}{|c|}{ Município } & $\mathbf{2 0 0 5}$ & $\mathbf{2 0 0 9}$ \\
\hline BA & $\begin{array}{l}\text { Vitória da } \\
\text { Conquista }\end{array}$ & Sim & Sim \\
\hline BA & Ilhéus & Não & Não \\
\hline MG & Juiz de Fora & Sim & Sim \\
\hline MG & Uberlândia & Sim & Sim \\
\hline RS & São Leopoldo & Sim & Sim \\
\hline RS & Novo Hamburgo & Não & Não \\
\hline MG & Poços de Caldas & Sim & Sim \\
\hline MG & Montes Claros & Não & Sim \\
\hline
\end{tabular}

Fonte: Munic 05 e 09 - IBGE

A Tabela 13 mostra uma discrepância entre os municípios e seus pares. No caso do primeiro par, ao passo que Vitória da Conquista possui pelo menos desde 2005 sistema informatizado para a gestão de sua política habitacional, o mesmo não ocorre com Ilhéus, que, ao menos até o ano de 2009, não possuía esse instrumento de gestão. No segundo par, a situação é diferente e, nesse caso, os dois municípios contavam, desde 2005, com o tipo de instrumental considerado.

No caso do terceiro par, São Leopoldo difere de Novo Hamburgo por apresentar, desde 2005, o tipo de sistema mencionado, ao passo que São Leopoldo nunca possuiu essa ferramenta. Por último, é interessante observar que, embora Montes Claros não possuísse um sistema informatizado desde 2005, tal como seu respectivo par, Poços de Caldas, parece que a cidade realizou significativo esforço para a sua implementação, contando com ele em 2009.

Os dados parecem indicar, mais uma vez, que a situação dos municípios nos quais se constatou maior grau de participação política tende a ser relativamente melhor do que naqueles nos quais se observou menor propensão à presença de políticas participativas.

Para complementar a análise, cabe considerar outra variável ligada à dimensão aqui aludida. Essa variável consiste na existência ou não de legislação específica sobre regularização fundiária. Esse tema é caro porque disciplina o uso dos espaços urbano e rural, de modo a guiar a expansão de cidades e de suas respectivas áreas rurais (Tabela 14 ). 
VAZ, A. C. N. Participação política, efeitos e resultados em políticas públicas: ...

Tabela 14

Existência de legislação específica que dispõe sobre regularização fundiária no município

\begin{tabular}{|c|l|c|c|}
\hline UF & \multicolumn{1}{|c|}{ Município } & 2005 & $\mathbf{2 0 0 9}$ \\
\hline BA & $\begin{array}{l}\text { Vitória da } \\
\text { Conquista }\end{array}$ & Sim & Não \\
\hline BA & Ilhéus & Não & Não \\
\hline MG & Juiz de Fora & Sim & Sim \\
\hline MG & Uberlândia & Sim & Não \\
\hline RS & São Leopoldo & Sim & Sim \\
\hline RS & Novo Hamburgo & Não & Não \\
\hline MG & Poços de Caldas & Não & Não \\
\hline MG & Montes Claros & Sim & Sim \\
\hline
\end{tabular}

Fonte: Munic 05 e 09 - IBGE

Os dados da Tabela 14 permitem algumas observações sobre os pares de municípios. No caso do primeiro par, a situação se destaca. Ilhéus nunca teve legislação específica nos moldes citados, ao passo que Vitória da Conquista possuía tal normativa em 2005, mas deixou de possuí-la em 2009. Esse aspecto pode indicar, dentre outras coisas, tipos de relações de força presentes localmente. No caso do segundo par, a situação é semelhante para a cidade de Uberlândia, já que a cidade possuía lei de regularização fundiária em 2005 e deixou de tê-la em 2009. 0 seu município par, Juiz de Fora, por sua vez, apresenta, pelo menos desde 2005, esse ferramental normativo como disciplinador da ocupação de terras.

Para o terceiro par, vemos que, enquanto São Leopoldo já contava, desde 2005, com a normativa considerada, o mesmo não ocorre com Novo Hamburgo, que parece nunca ter possuído tal instrumental. Por último, o par Poços de Caldas/ Montes Claros mostra uma inversão da lógica até então configurada. Neste caso, a cidade na qual se observou menor propensão participativa sempre contou com lei de regularização fundiária, ao passo que Poços de Caldas não esse instrumento.

Uma segunda dimensão de análise do campo de planejamento e gestão pública está ligada aos aspectos de investimento em gestão pelos municípios, bem como no reflexo desses investimentos sob a situação tributária e de oferta dos serviços públicos. A primeira variável a ser analisada concerne à receita tributária per capita dos municípios. A receita tributária depende inteiramente do próprio gestor local e está estreitamente relacionada à sua capacidade administrativa e de negociação com a sociedade. A Tabela 15 fornece informações sobre esse indicador para os casos em pauta: 
Tabela 15

Receita tributária per capita dos municípios da amostra

\begin{tabular}{|c|l|c|c|c|}
\hline UF & \multicolumn{1}{|c|}{ Município } & $\mathbf{2 0 0 0}$ & $\mathbf{2 0 0 4}$ & $\mathbf{2 0 0 6}$ \\
\hline BA & $\begin{array}{l}\text { Vitória da } \\
\text { Conquista }\end{array}$ & 78,4 & 89,2 & 98,4 \\
\hline BA & Ilhéus & 59,4 & 68,3 & 78,1 \\
\hline MG & Juiz de Fora & 112 & 165,4 & 201,1 \\
\hline MG & Uberlândia & 101 & 172,1 & 210,4 \\
\hline RS & São Leopoldo & 89,1 & 140,5 & 162,4 \\
\hline RS & Novo Hamburgo & 69,3 & 89,5 & 142,3 \\
\hline MG & Poços de Caldas & 107,5 & 204,8 & 217,0 \\
\hline MG & Montes Claros & 47,7 & 72,4 & 92,7 \\
\hline
\end{tabular}

Fonte: IpeaDATA. Disponível em: <www.ipeadata.gov.br>. Acesso em: 25 maio 2011.

A receita tributária encontra divisão relevante no conjunto dos casos. Em primeiro lugar, o primeiro par de municípios mostra que, para ambos os casos, existe uma tendência de aumento da receia tributária per capita ao longo dos anos, embora seja notável que os valores observados para Vitória da Conquista são maiores do aqueles observados para Ilhéus. No caso do segundo par, a peculiaridade está em que, embora a receita tributária per capita de ambos os municípios seja semelhante, em Uberlândia há um crescimento maior do que em Juiz de Fora no período considerado.

O terceiro par mostra indicativos muito parecidos com os do primeiro par: para ambos os municípios ocorre um crescimento dos valores e os valores observados para o município com maior grau de participação política são sistematicamente maiores do que os do outro município. No caso do quarto par, essa tendência é ainda maior, já que a diferença entre os valores do município com maior tendência à adoção de políticas participativas, Poços de Caldas, são sistematicamente maiores do que o par, Montes Claros.

Finalmente, a última comparação entre os municípios, relativa ao planejamento de políticas públicas e gestão, é feita por um conjunto de quatro indicadores específicos, a saber: Existência de cadastro e/ou banco de dados da saúde informatizado, Existência de cadastro e/ou banco de dados da educação informatizado, Existência de cadastro e informatização de patrimônio e, por fim, Existência de Tesouraria/ Contabilidade Informatizados. Como já foi afirmado no caso da informatização de cadastros habitacionais, políticas de informatização são, ao mesmo tempo, um importante ferramental para o planejamento público, mas geralmente têm custos elevados de implantação e manutenção. Funcionam, neste sentido, como um indicador da vontade efetiva do gestor de profissionalizar, 
VAZ, A. C. N. Participação política, efeitos e resultados em políticas públicas: ...

sistematizar e tratar eficientemente as informações para planejamento e gestão de políticas públicas locais (Tabela 16).

Tabela 16

Existência de políticas de informatização de bancos de dados para áreas diversas nos municípios da amostra

\begin{tabular}{|c|l|c|c|c|c|}
\hline UF & Município & $\begin{array}{c}\text { Existência de } \\
\text { cadastro e/ou } \\
\text { banco de dados } \\
\text { da saúde } \\
\text { informatizado }\end{array}$ & $\begin{array}{c}\text { Existência de } \\
\text { cadastro e/ou } \\
\text { banco de dados } \\
\text { da educação } \\
\text { informatizado }\end{array}$ & $\begin{array}{c}\text { Existência de } \\
\text { cadastro e } \\
\text { informatização } \\
\text { de patrimônio }\end{array}$ & $\begin{array}{c}\text { Existência de } \\
\text { Tesouraria/ } \\
\text { Contabilidade } \\
\text { Informatizados }\end{array}$ \\
\hline BA & $\begin{array}{l}\text { Vitória da } \\
\text { Conquista }\end{array}$ & $\operatorname{sim}$ & $\operatorname{sim}$ & $\operatorname{sim}$ & Sim \\
\hline BA & Ilhéus & não & não & não & Sim \\
\hline MG & Juiz de Fora & $\operatorname{sim}$ & $\operatorname{sim}$ & não & Sim \\
\hline MG & Uberlândia & sim & sim & sim & Não \\
\hline RS & São Leopoldo & $\operatorname{sim}$ & não & não & Sim \\
\hline RS & Novo Hamburgo & não & não & sim & Não \\
\hline MG & Poços de Caldas & sim & sim & não & Não \\
\hline MG & Montes Claros & sim & não & não & Sim \\
\hline
\end{tabular}

Fonte: SNIC, 1999. Disponível em: <www.cidades.gov.br>. Acesso em: 25 maio 2011.

Os dados da Tabela 16 sobre a capacidade de planejamento dos municípios analisados mostram, em primeiro lugar, ao lidarmos com a variável referente à existência de cadastro ou banco informatizado na área de saúde, os municípios se diferenciam. No caso dos primeiro e terceiro pares, apenas os municípios com maior grau de participação política, Vitória da Conquista e São Leopoldo, declararam possuir o sistema. Nos outros pares, ambos os municípios declararam possuí-lo. Com relação à variável de existência de cadastro ou banco de dados informatizado para a área de educação, o mesmo padrão anterior parece repetir-se. Entretanto, no terceiro par, ambos os municípios declararam não possuir esse sistema.

A análise da terceira variável, existência de cadastro informatizado do patrimônio, sugere uma inversão na lógica das duas anteriores. À exceção do primeiro par, em que o município com maior grau de participação possui este tipo de sistema e seu par, não, os segundo e terceiro pares indicam situação contrária: municípios com menor propensão participativa possuem sistema informatizado para registro patrimonial, ao passo que os "mais participativos" não possuem. Em último lugar, no que tange à variável existência de tesouraria/contabilidade informatizados, os três primeiros pares mostram um padrão consistente com a 
tendência apresentada pelos dados de melhor oferta de bens e serviços pelos municípios com maior grau de participação política. Apenas o quarto par, Poços de Caldas/ Montes Claro, revela uma inversão tal como percebida especificamente no par anterior, sendo que esta última cidade possui o tipo de sistema aqui considerado, e a primeira, não.

Uma vez mais, se tomarmos em consideração o conjunto de dados apresentados, é possível perceber claramente que existe um determinado padrão no tocante à relação entre a propensão à abertura para participação política e os resultados em políticas públicas e indicadores específicos de desempenho gerencial. Essa relação, pelo menos na maioria dos casos, tem se revelado positiva, isto é, em cidades com maior propensão participativa, tende-se a encontrar, também, melhores resultados nos moldes considerados. Especialmente na área gerencial, esse fator é importante, já que este campo prediz a capacidade do governo local de elaborar, implementar, gerir, administrar, monitorar e avaliar políticas e resultados no seu território, contribuindo, principalmente, para a responsabilidade fiscal quanto aos gastos públicos e quanto à efetiva melhoria da "qualidade de vida" dos cidadãos.

\section{Considerações Finais}

É possível dizer que existe relação entre incremento de políticas de participação social e melhoria em resultados de políticas públicas? A resposta é dúbia: sim e não. Por um lado, no que concerne ao "sim", não é difícil notar, através da metodologia aqui adotada e da comparação dos dados e indicadores de resultados em políticas públicas e gerenciais, que municípios nos quais se constatou maior propensão participativa, são, também, aqueles que, sistematicamente, tenderam a apresentar melhores resultados no âmbito dos indicadores analisados. Essa observação é válida para as três dimensões de resultados aqui apresentadas: saúde e saneamento básico, assistência social e capacidades gerencial e administrativa.

Ademais, a importância das diferenças observadas nos resultados é ainda ressaltada pelo fato de que foram comparados municípios com características factualmente semelhantes no tocante a algumas dimensões importantes, como a econômica, a social e a demográfica. Parece que, ao analisarmos o histórico do desenvolvimento dos municípios nestas dimensões, a propensão participativa tende a se ligar a algumas diferenciações, como o tipo de partido ou grupo político no poder e o grau de desenvolvimento econômico apresentado. Vitória da Conquista e Ilhéus, por exemplo, podem ser tomados como clássicos casos para ilustrar tal ponto. Ambas são semelhantes em termos socio-demográficos, mas se diferenciaram, ao longo do tempo, quanto à política e à economia. Por vários anos, 
Vitória da Conquista teve a alternância no poder de grupos de centro-direita e de centro-esquerda, ao passo que Ilhéus sempre teve a presença de grupos tradicionalistas de direita. Na mesma linha, muito embora as economias dessas cidades tenham tido por base atividades ligadas à agricultura e pecuária, Vitória da Conquista buscou diversificação nas atividades, especialmente com o desenvolvimento do setor de serviços e de industrialização. Em Ilhéus, a base econômica parece ainda se restringir, basicamente às atividades ligadas à agricultura, especialmente a produção do cacau. A essas discrepâncias, somam-se as diferenças observadas nos resultados em políticas públicas e gerenciais. Vitória da Conquista apresentou resultados sistematicamente melhores do que Ilhéus nesse sentido, para todas as dimensões analisadas.

Dito isso, podemos, então, proceder à parte "não" de nossa resposta. Através dos dados apresentados, sustento que não é possível estabelecer qualquer relação de causalidade entre as duas categorias aqui analisadas, participação política e resultados em políticas públicas e gerenciais. O máximo que as informações permitem indicar consiste na pressuposição de que municípios com maior propensão participativa tendem a apresentar melhores resultados em políticas públicas. No entanto, não é possível dizer em que medida, em que sentido, ou mesmo se, efetivamente, existe alguma causalidade entre as variáveis.

Essa questão carece de maior aprofundamento analítico. Hoje, sabemos que instituições participativas estão distribuídas de maneira variada nos municípios brasileiros e implicam mudanças nas regras do jogo em políticas públicas, pois "atravessam" diametralmente os processos de tomada de decisão governamentais. Com isso, podemos supor (e, neste caso, com um certo grau de certeza), que sua presença implica em um impacto nestas regras e em seus respectivos resultados.

Entretanto, até hoje temos nos especializado em conhecer o funcionamento destas instituições, como nos casos dos estudos aprofundados sobre Conselhos Gestores e o Orçamento Participativo, mas não sabemos quase nada, na verdade, para além das pressuposições apresentadas neste trabalho, sobre o quanto, efetivamente, a participação política contribui para resultados em políticas públicas e gerenciais específicas. Não existe qualquer tipo de mensuração - e sequer padrões específicos para fazê-lo - no tocante ao peso efetivo que a participação política tem nas políticas públicas. Disso resulta a sensação de que, na verdade, estamos tateando, em ambiente nebuloso, nosso objeto de estudo. Estamos pressupondo que ele causa efeitos e influências, mas não temos como efetivamente prová-los tendo por base um modelo generalizável que perpasse a super especialização característica dos estudos até agora empreendidos nessa direção, seja por tipo de instituição, seja por tipo de caso.

O que os estudos sobre participação política no Brasil necessitam, neste momento, é diversificar suas análises, potencializando a compreensão do papel 
efetivo da participação política nos resultados das políticas às quais se associam. Será que a participação tem mesmo alguma participação? Quanto ela vale, efetivamente?

\section{Referências Bibliográficas}

ABERS, R. N; KECK, M. Representando a diversidade? Estado e associações civis nos conselhos gestores. In: Anais II Seminário Nacional Movimentos Sociais, Participação e Democracia, Florianópolis, 2007.

AVRITZER, L. Teoria democrática e deliberação pública. In: Lua Nova. n 50. Cedec, São Paulo, 2000.

. O orçamento participativo e a teoria democrática: um balanço crítico. In:

AVRITZER, L; NAVARRO, Z. (Orgs.). A Inovação Democrática no Brasil. São Paulo: Cortez, 2003.

Reforma Política e Participação no Brasil. In: AVRIZER, L; ANASTASIA, F. (Orgs.). Reforma Política no Brasil. Belo Horizonte: Editora UFMG, 2006, v. 1, p. 1 271.

. "Sociedade Civil, Instituições Participativas e Representação: da Autorização

à Legitimidade da Ação". Dados, Rio de Janeiro, v. 50, p. 443-464, 2007.

. Instituições participativas e desenho institucional: algumas considerações sobre a variação da participação no Brasil democrático. Opinião Pública, Campinas, vol. $14, n^{\circ} 1$, Junho 2008 , p. 43-64.

. Participatory Institutions in Democratic Brazil. Baltimore: Johns Hopkins University Press, 2009.

AVRITZER, L; NAVARRO, Z. (Orgs.) A inovação democrática no Brasil. São Paulo: Editora Cortez, v. 1, 2003.

AVRITZER, L; PIRES, R. R. Orçamento participativo, efeitos distributivos e combate à pobreza. Teoria \& Sociedade, Belo Horizonte, p. 68-89, 2005.

AVRITZER, L; VAZ, A. C. N. Accountability and the creation of local spaces for participation in Latin America. Paper presented for the OAS Seminar Project on the Consequences of the Descentralization Process in the Americas and the Challenges 
VAZ, A. C. N. Participação política, efeitos e resultados em políticas públicas: ...

to Democratic Governance. Accountability and the Creation of Public Spaces at the Local Level, 2008. Disponível em: <www.civil-

society.oas.org/English/Decentralization_1-Accountability.doc>. Acesso em: [26 maio 2011].

AVRITZER, L; WAMPLER, B. 2008. The expansion of participatory budgeting in Brazil: an analysis of the current cases base upon design and socio-economic indicators. Relatório de pesquisa Projeto OP Banco Mundial/MDP-ESA, 2008. Mimeo.

BAIOCCHI, G. S; CHAUDURI, P. H. e M. K. SILVA. Evaluating empowerment: participatory budgeting in Brazilian municipalities. University of Massachusetts, 2006. Disponível em:

<http://www.people.umass.edu/baiocchi/papers/PB_Report.pdf>. Acesso em: [15 mar. 2010].

BENEVIDES, M. V. M. A cidadania ativa: referendo, plebiscito e iniciativa popular. São Paulo: Ática, 1991.

BOSCHI, R. R. A arte da associação: Política de base e democracia no Brasil. Rio de Janeiro: IUPERJ/VERTICE, 1987.

BOULDING, C. and WAMPLER, B. Voice, Votes and Resources: Evaluating the effect of participatory democracy on well-being. World Development v. 38, $n^{\circ} 1$, p. 135 , Jan. 2009.

BRASIL. Constituição da República Federativa do Brasil, 1988.

CAMPOS, G. A. Orçamento Participativo de São Paulo: limiar da participação e redistribuição na megalópole. In: MARQUETTI, A; CAMPOS, G. e PIRES, R. (Orgs.). Democracia Participativa e Redistribuição: análise de experiências de orçamento participativo. São Paulo: Ed. Xamã, 2008.

COELHO, V. S. R. P. Brazil's Health Councils: The Challenge of Building Participatory Political Institutions. IDS Bulletin, Sussex, v. 35, n. 2, p. 33-39, 2004.

COELHO, V. S. P. \& NOBRE, M. (Orgs.). Participação e deliberação: teoria democrática e experiências institucionais no Brasil contemporâneo. São Paulo: Ed. 34, 2004.

COHEN, J. L. and ARATO, A. Civil Society and Political Theory, Cambridge MA: MIT Press, 1994.

COSTA, S. Categoria analítica ou passe-partout político normativo: notas bibliográficas sobre o conceito de sociedade civil. BIB, Anpocs, $n^{\circ} 43$. São Paulo:

Ed. Relume - Dumará. p. 3-25, 1997. 
CUNHA, E. S. M. Aprofundando a Democracia: O Potencial dos Conselhos de Políticas e Orçamentos Participativos. Dissertação (mestrado). Departamento de Ciência Política, UFMG, Belo Horizonte, 2004.

- O potencial de conselhos de políticas e Orçamentos Participativos para o aprofundamento democrático. In: DAGNINO, E. e TATAGIBA, L. (Orgs.). Democracia, sociedade civil e participação. Chapecó: Argos, 2007, p. 25-44.

DAGNINO, E. Sociedade civil e espaços públicos no Brasil. In: DAGNINO, E. (Org), pp. 9-15. Sociedade civil e espaços públicos no Brasil. São Paulo: Paz e Terra, 2002.

DAGNINO, E; TATAGIBA, L. (Orgs.). Democracia, sociedade civil e participação. Chapecó: Argos, 2007.

DOIMO, A. M. A vez e a voz do popular: movimentos sociais e participação política no Brasil pós 70. Rio de Janeiro: RelumeDumará/ANPOCS, 1995.

FARIA, C. F. O Estado em Movimento: Complexidade Social e Participação Política no Rio Grande do Sul. Tese (Doutorado), Departamento de Ciência Política UFMG, 2005.

Fóruns Participativos, controle democrático e a qualidade da democracia no Rio Grande do Sul: a experiência do governo Olívio Dutra (1999-2002). Opinião Pública, v. 12, p. 378-406, 2006.

- O processo decisório do Orçamento Participativo no Rio Grande do Sul: da deliberação pública à representação política. In: DAGNINO, E. e TATAGIBA, L. (Orgs.). Democracia, Sociedade Civil e Participação. Chapecó: Argos Editora Universitária, 2007.

FUNG . A. Receitas para esferas públicas: oito desenhos institucionais e suas conseqüências. In: COELHO, V. S. P. \& NOBRE, M. (Orgs.). Participação e deliberação: teoria democrática e experiências institucionais no Brasil contemporâneo. São Paulo: ed. 34, 2004.

FUNG, A. and E. O. WRIGHT, (Eds) Deepening Democracy: Institutional Innovation in Empowered Participatory Governance, London: Verso, 2003.

GRAZIA de G; TORRES R. A. C. Experiência de Orçamento Participativo no Brasil: Período de 1997 a 2000. São Paulo: Editora Vozes, 2003.

GOHN, M. G. Conselhos gestores e participação política. São Paulo: Cortez, 2001.

. Os conselhos municipais e a gestão urbana, In: SANTOS JUNIOR, O. A; RIBEIRO, L. C. Q; AZEVEDO, S. (Orgs.). Governança democrática e poder local: a experiência dos conselhos municipais no Brasil. Rio de Janeiro: Revan/Fase, 2004. 
VAZ, A. C. N. Participação política, efeitos e resultados em políticas públicas: ...

GUGlano, A. A; LOCK, R. B; ORSATO, A; PEREIRA, A. L. Processos participativos e estratégias de redistribuição: resgatando o OP em Pelotas, RS (1984-1985). In: MARQUETTI, A; CAMPOS, G; e PIRES, R. (Orgs.). Democracia Participativa e Redistribuição: análise de experiências de orçamento participativo. São Paulo: Ed. Xamã, 2008.

HELD, D. Democracy and the Global Order: From the Modern State to Cosmopolitan Governance. Stanford: Polity Press and Stanford University Press, 1995.

JACOBI, P. Movimentos sociais e políticas públicas. São Paulo: Cortez Editora, 1989.

KECK, M. The Workers' Party and Democratization in Brazil. New Haven: Yale University Press, 1992.

KOWARICK, L. Capitalismo e Marginalidade na América Latina. Rio de Janeiro: Paz e Terra, 1975.

LAVALLE, A. G; HOUTZAGER, P; CASTELLO, G. Democracia, Pluralização da Representação e Sociedade Civil. Lua Nova - Revista de Cultura e Política, v. 67, $n^{\circ}$ 67, p. 49-103, 2006.

LÜCHMANN, L. H. H. Possibilidades e limites da democracia deliberativa: a experiência do Orçamento Participativo de Porto Alegre. Tese (doutorado) Campinas, Departamento de Ciência Política, Unicamp, 2002a.

Os Conselhos Gestores de Políticas Públicas: desafios do desenho institucional. Ciências Sociais UNISINOS, 38(161):43-79, 2002b.

MAINWARING, S. Rethinking Party Systems in the Third Wave of Democratization: The Case of Brazil. Stanford: Stanford University Press, 1999.

MARQUETTI, A. A. Participação e Redistribuição: o Orçamento Participativo em Porto Alegre. In: AVRITZER, L; NAVARRO, Z. (Orgs.). A inovação democrática no Brasil. São Paulo: Cortez Editora, v. 1, 2003, p. 129-156.

. The characteristics of the Brazilian cities with Participatory Budgeting In: Primeiras Jornadas de Economia Regional Comparada, Porto Alegre. Anais das Primeiras Jornadas de Economia Regional Comparada, v. 1. p. 1-33, 2005.

. Orçamento Participativo, redistribuição e finanças municipais: a experiência de Porto Alegre entre 1989 e 2004. In: MARQUETTI, A; CAMPOS, G; PIRES, G. (Orgs.). Democracia Participativa e Redistribuição: análise de experiências de orçamento participativo. São Paulo: Xamã VM Editora LTDA, 2008, p. 31-54. 
MARQUETTI, A; CAMPOS, G. e PIRES, R. (Orgs.). Democracia Participativa e Redistribuição: análise de experiências de orçamento participativo. São Paulo: Ed. Xamã, 2008.

OXHORN, P. Unraveling the puzzle of decentralization, In: OXHORN, P. TULCHIN, J. and SELEE, A. (Eds.) Decentralization, Democratic Governance, and Civil Society in Comparative Perspective: Africa, Asia, and Latin America. Baltimore, MD: Johns Hopkins University Press, 2004.

PATEMAN, C. Participação e teoria democrática. Rio de janeiro: Paz e Terra, 1992.

PIRES, R. Regulamentação da participação no OP em Belo Horizonte: eficiência distributiva aliada ao planejamento urbano. In: MARQUETTI, A; CAMPOS, G. e PIRES, R. (Orgs.) Democracia Participativa e Redistribuição: análise de experiências de orçamento participativo. São Paulo: Ed. Xamã, 2008.

PUTNAM, R. Making Democracy Work: Civic Traditions in Modern Italy. Princeton: Princeton University Press, 2002, 280 pp.

SANTOS, B. S. Reinventar a Democracia. Cadernos Democráticos 4. Portugal: Gradiva, 1998.

SANTOS, B. S; AVRITZER, L. Para Ampliar o Cânone Democrático. In: SANTOS, B. S. (Org.). Democratizar a Democracia. Rio de Janeiro: Civilização Brasileira, 2003, p. 01.678 .

SELEE, A; TULCHIN, J. S. (eds). Decentralization and Democratic Governance in Latin America. Woodrow Wilson International Centre for Scholars, 2004.

SKIDMORE, T. E. Brazil: Five Centuries of Change. Oxford: Oxford University Press, 1999.

TATAGIBA, L. Os conselhos gestores e a democratização das políticas públicas no Brasil. In: DAGNINO, E. (Org). Sociedade civil e espaços públicos no Brasil. São Paulo: Paz e Terra. 2002, pp. 47-105.

A institucionalização da participação: os conselhos municipais de políticas públicas na cidade de São Paulo. In: AVRITZER, L. (Org.). A participação em São Paulo. São Paulo: UNESP, 2004, p. 323-370.

VITALE, D. Democracia direta e poder local: a experiência brasileira do orçamento participativo. In: COELHO, V. S. R. P. e NOBRE, M. (Orgs.) Participação e Deliberação: Teoria Democrática e Experiências Institucionais no Brasil Contemporâneo. São Paulo: Editora 34, 2004, pp. 239-254. 
VAZ, A. C. N. Participação política, efeitos e resultados em políticas públicas: ...

VAZ, A. C. N. Repensando a participação política: uma análise do estado da arte à luz da problemática da representação política nos Conselhos Gestores. Revista do Observatório do Milênio, Belo Horizonte, v. 1, n² 2, 2009, p. 56-80.

. Da participação à qualidade da deliberação em fóruns públicos: o itinerário da literatura sobre Conselhos no Brasil. In: PIRES, R. R. C. (Org). A efetividade das Instituições Participativas no Brasil: perspectivas, abordagens e estratégias de avaliação. Série: Diálogos para o Desenvolvimento, v. 7, 2011 (no prelo).

VAZ, A. C. N; PIRES, R. R. C. Comparações entre municípios: avaliação dos efeitos da participação por meio de pares contrafactuais. In: PIRES, R. R. C. (Org). A efetividade das Instituições Participativas no Brasil: perspectivas, abordagens e estratégias de avaliação. Série: Diálogos para o Desenvolvimento, v. 7, 2011 (no prelo).

WAMPLER, B; AVRITZER, L. Participatory publics: civil society and new institutions. Comparative Politics, New York, v. 1, 2004, p. 1.

. The expansion of participatory budgeting in Brazil: an analysis of the current cases based upon design and socio-economic indicators. Relatório final de consultoria Banco Mundial, contrato MDP-ESA/Banco Mundial, 2008, 48 p. Mimeo.

WARREN, M. Democracy and Associations. Princeton: Princeton University Press, 2001.

ZAMBONI, Y. Participatory budgeting and local governance: an evidence-based evaluation of participatory budgeting experiences in Brazil. Working paper, 2007. Disponível em:

<http://siteresources.worldbank.org/INTRANETSOCIALDEVELOPMENT/Resources/ Zamboni.pdf>. Acesso em: [mar. 2010].

Alexander Cambraia N. Vaz - cambraia04@ufmg.br

Recebido para publicação em outubro de 2009. Aprovado para publicação em abril de 2011. 